Cochrane Database of Systematic Reviews

\title{
Singing as an adjunct therapy for children and adults with cystic fibrosis (Review)
}

Irons JY, Petocz P, Kenny DT, Chang AB

Irons JY, Petocz P, Kenny DT, Chang AB.

Singing as an adjunct therapy for children and adults with cystic fibrosis.

Cochrane Database of Systematic Reviews 2019, Issue 7. Art. No.: CD008036.

DOI: 10.1002/14651858.CD008036.pub5.

www.cochranelibrary.com 
TABLE OF CONTENTS

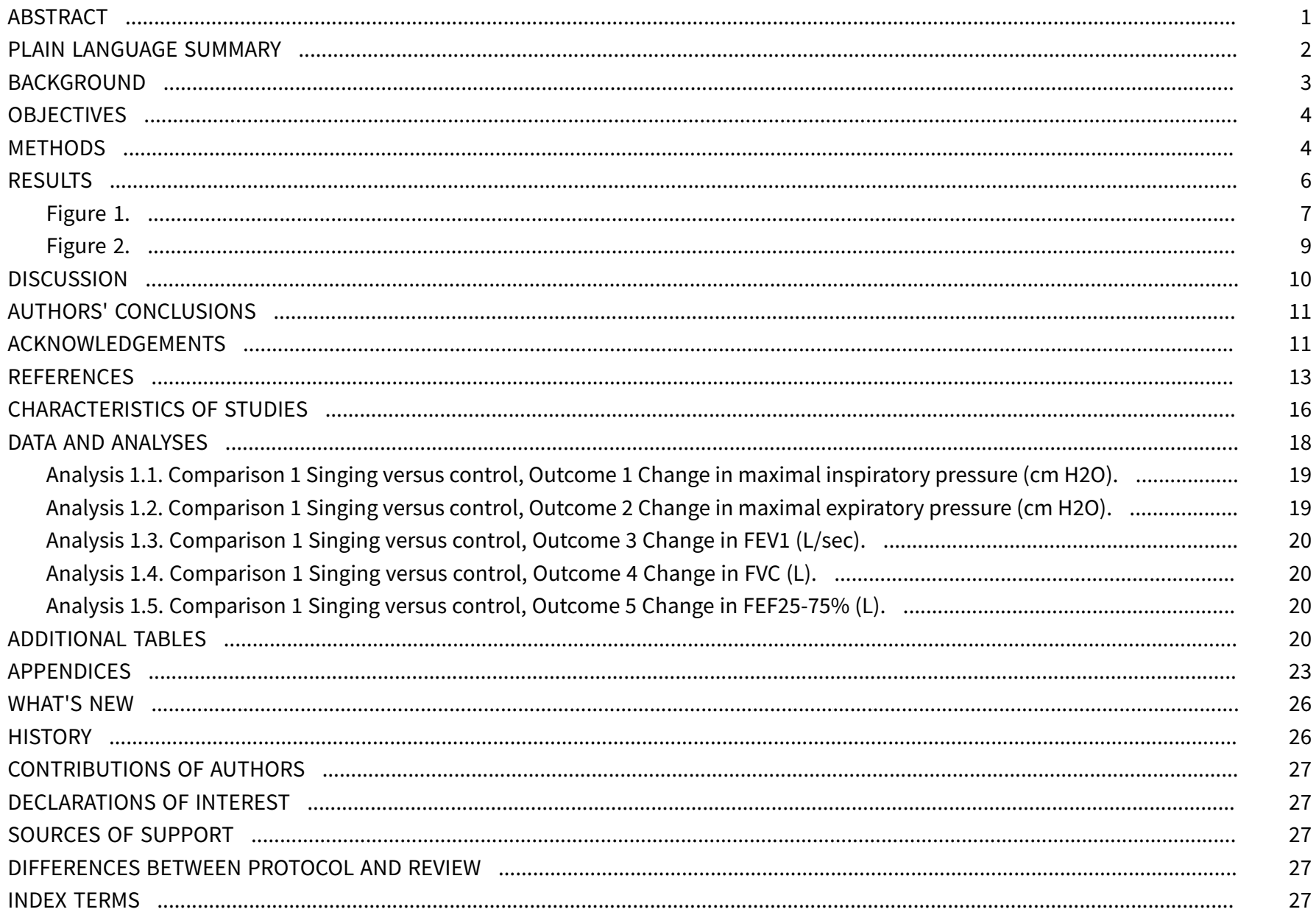


[Intervention Review]

\title{
Singing as an adjunct therapy for children and adults with cystic fibrosis
}

\author{
J. Yoon Irons ${ }^{1}$, Peter Petocz 2 , Dianna Theadora Kenny ${ }^{3}$, Anne B Chang 4 \\ 1Health and Social Care Research Centre, University of Derby, Derby, UK. 2Department of Statistics, Macquarie University, Sydney, \\ Australia. ${ }^{3}$ Behavioural and Social Sciences in Health, Faculty of Health Sciences, University of Sydney, Lidcombe, Australia. ${ }^{4}$ Child \\ Health Division, Menzies School of Health Research, Charles Darwin University, Darwin, Australia
}

Contact: J. Yoon Irons, Health and Social Care Research Centre, University of Derby, Derby, UK. y.irons@derby.ac.uk.

Editorial group: Cochrane Cystic Fibrosis and Genetic Disorders Group.

Publication status and date: New search for studies and content updated (no change to conclusions), published in Issue 7, 2019.

Citation: Irons JY, Petocz P, Kenny DT, Chang AB. Singing as an adjunct therapy for children and adults with cystic fibrosis. Cochrane Database of Systematic Reviews 2019, Issue 7. Art. No.: CD008036. DOI: 10.1002/14651858.CD008036.pub5.

Copyright @ 2019 The Cochrane Collaboration. Published by John Wiley \& Sons, Ltd.

\section{A B S T R A C T}

\section{Background}

Cystic fibrosis is a genetically inherited, life-threatening condition that affects major organs. The management of cystic fibrosis involves a multi-faceted daily treatment regimen that includes airway clearance techniques, pancreatic enzymes and other medications. Previous studies have found that compliance with this intensive treatment is poor, especially among adolescents. Because of both the nature and consequences of the illness and the relentless demands of the treatment, many individuals with cystic fibrosis have a poor quality of life. Anecdotal reports suggest that singing may provide both appropriate exercise for the whole respiratory system and a means of emotional expression which may enhance quality of life. This is an update of a previously published review.

\section{Objectives}

To evaluate the effects of singing as an adjunct therapy to standard treatment on the quality of life, morbidity, respiratory muscle strength and pulmonary function of children and adults with cystic fibrosis.

\section{Search methods}

We searched the Group's Cystic Fibrosis Trials Register and the Cochrane Central Register of Controlled Trials. Date of latest search: 07 January 2019.

We also searched major allied complementary data bases, and clinical trial registers. Additionally, we handsearched relevant conference proceedings and journals. Date of latest search: 28 March 2019.

\section{Selection criteria}

Randomised controlled trials in which singing (as an adjunct intervention) is compared with either a control intervention (for example, playing computer games or doing craft activities) or no singing in people with cystic fibrosis.

\section{Data collection and analysis}

Results of searches were reviewed against pre-determined criteria for inclusion. Only one eligible trial was available for analysis.

\section{Main results}

Since only one small study ( $n=40$ ) was included, no meta-analysis could be performed. The included randomised controlled study was of parallel design and undertaken at two paediatric hospitals in Australia. The study evaluated the effects of a singing program on the quality of life and respiratory muscle strength of hospitalised children with cystic fibrosis (mean age 11.6 years, 35\% male). While the singing group received eight individual singing sessions, the control group participated in preferred recreational activities, such as playing computer games or watching movies. This study was limited by a small sample size (51 participants) and a high drop-out rate (21\%). 
There were no differences between the groups at either post-intervention or follow-up; although by the end of treatment there were some improvements in some of the domains of the quality of life questionnaire Cystic Fibrosis Questionnaire-Revised (e.g. emotional, social and vitality domains) for both singing and control groups. For the respiratory muscle strength indices, maximal expiratory pressure at followup (six to eight weeks post-intervention) was higher in the singing group, mean difference 25.80 ( $95 \%$ confidence interval 5.94 to 45.66 ). There was no difference between groups for any of the other respiratory function parameters (maximal inspiratory pressure, spirometry) at either post-intervention or follow-up. No adverse effects were observed in the singing group; adverse events for the control group were not reported in the paper.

\section{Authors' conclusions}

There is insufficient evidence to determine the effects of singing on quality of life or on the respiratory parameters in people with cystic fibrosis. However, there is growing interest in non-medical treatments for cystic fibrosis and researchers may wish to investigate the impact of this inexpensive therapy on respiratory function and psychosocial well-being further in the future.

\section{PLAIN LANGUAGE SUMMARY}

\section{The effects of singing on lung function and quality of life in children and adults with cystic fibrosis}

\section{Review question}

We reviewed the evidence of the effects of using singing as an add-on treatment in children and adults with cystic fibrosis.

\section{Background}

People with cystic fibrosis are at risk of chest infections due to abnormally thick mucus in their airways. Airway clearance is therefore an important part of managing the condition. Increasing anecdotal reports suggest that singing may support lung function and enhance quality of life in people with cystic fibrosis. We searched for trials using the standard search methods of the Cochrane Cystic Fibrosis and Genetic Disorders Group, and conducted extensive searches in other relevant databases and publications. This is an update of a previously published review.

\section{Search date}

The evidence is current to: 07 January 2019.

\section{Study characteristics}

The review includes one study with 40 children with cystic fibrosis aged between seven and 17 years of age. This study compared a specially designed singing intervention with other non-physical leisure activities (recreation) and children were selected for the singing or the recreation program randomly. The study lasted two weeks and children were followed up for between six and eight weeks. The study assessed the impact of singing on respiratory muscle strength, quality of life and lung function tests.

\section{Key results}

Participants from both the singing and recreation groups reported some improvement in quality of life measurements. Participants in the singing group showed a greater increase in maximal expiratory pressure (a substitute measure of respiratory muscle strength test), while there was no improvement in this outcome for those in the recreation group. No adverse events were reported. There is currently not enough evidence to assess the effect of singing on clinical outcomes in people with cystic fibrosis. Future studies using robust methods are needed to assess the possible effects of singing for people with cystic fibrosis

\section{Quality of the evidence}

The included study was limited by the small number of participants (only 51 participants enrolled and only 40 were analysed) and a high drop-out rate $(21 \%)$. We also think the fact that the young people who were enrolled in the study were keen to sing, could have affected the study results. 


\section{B A C K G R O U N D}

\section{Description of the condition}

Cystic fibrosis (CF) is a genetically inherited life-threatening condition that affects major organs, such as the lungs, pancreas, liver and kidneys. Individuals with CF produce abnormally excessive thick mucus in the airways, which makes them more susceptible to lung diseases. Repeated infections in the airways lead to irreversible lung damage (Phelan 1994).

The management of CF involves a multifaceted daily treatment regimen that usually includes airway clearance techniques, physical exercise, pancreatic enzymes and other medications, as well as hospital admissions. Such an intensive treatment regimen may have a negative psychosocial impact on children and adolescents (Glasscoe 2008), particularly on adolescents (D'Auria 2000). Previous studies have found that individuals with CF may have poor quality of life (QoL) (Quittner 2008).

\section{Description of the intervention}

For individuals with $\mathrm{CF}$, the respiratory muscles play an important role in maintaining lung health (Reid 2008; Sawyer 1993). Respiratory muscle strength is vital for airway clearance techniques, as it helps to generate effective cough to expectorate secretion (Chang 2006; Widdicombe 2006). Respiratory muscle function also affects exercise capacity in people with CF (Enright 2004), and greater levels of exercise capacity are correlated with lower levels of mortality (Nixon 1992). To improve respiratory muscle function in CF, conventional treatment uses inspiratory muscle training (IMT) devices. Some research has shown that an IMT program can improve respiratory muscle function in children (Sawyer 1993); however, a recent systematic review detected only weak evidence that conventional IMT devices were beneficial (Reid 2008). Using an IMT device can also be seen as another chore for individuals with CF, given the complexity of the daily treatment regimen. In contrast, a singing intervention may provide an enjoyable activity which would also have therapeutic benefits.

The dome-shaped diaphragm is a primary inspiratory muscle, and separates the thorax from the abdomen (Titze 1994). The diaphragm flattens as it contracts, and expands the thorax, thus increasing air intake by increasing lung volume (Leanderson 1987; Leanderson 1988). Sundberg found that singing requires greater use of vital lung capacity than normal speech, due to the longer phrases contained in songs (Sundberg 1987). Singers, therefore, need to use their lung capacity efficiently in order to sustain long phrases while singing. Classical singers use almost $100 \%$ of their vital lung capacity at the beginning of long phrases, so that extra breaths are not necessary (Sundberg 1987). Although not all trained singers use identical breathing behaviours, opera singers have been found to have highly consistent breathing strategy and greater movement of the rib cage and abdomen while singing (Thomasson 1999).

Anecdotal reports suggest that singing may be beneficial for people with chronic respiratory diseases (Elliott 2009; NHS Choices 2011; Stacy 2002).

Current literature suggests that singing interventions based on diaphragmatic breathing can improve or maintain the respiratory muscle functions in people with chronic obstructive pulmonary disease (COPD) (Bonilha 2009), multiple sclerosis (Wiens 1999) and Parkinson's disease (Di Benedetto 2009). In these studies, the respiratory muscle strength (using maximal inspiratory pressure (MIP) and maximal expiratory pressure (MEP)) were measured as the indicators reflecting changes in the respiratory muscle strength attributed to the singing intervention.

Singing can also reduce fear, anxiety and pain perception and improve mood (Kenny 2004; Unwin 2002). Further, singing can provide not only health benefits but also enjoyment. Studies found that when singing or music were part of a breathing exercise, participants with asthma demonstrated better treatment compliance due to greater enjoyment, which enhanced their motivation (Fukuda 2000; Lipawen 2000).

Additionally, a number of anecdotal reports attest to the benefits of singing in enhancing the quality of life (QoL) of people with chronic lung diseases (Stacy 2002). Studies investigating the effects of a singing or music program on the lung health and QoL of people with COPD (Bonilha 2009; Lord 2010), emphysema (Engen 2005) and asthma (Wade 2002) indicate that singing can be an enjoyable, low-cost and low-risk intervention, which supports lung health and enhances QoL.

\section{How the intervention might work}

Studies show that singing requires a regulation of exhaled air flow and promotes the use of vital capacity to the fullest possible extent (Collyer 2009 Sundberg 1987). Similar to other airway clearance techniques, such as the active cycle of breathing technique (Robinson 2010), singing promotes good posture (relaxed neck and shoulders), control of breathing, and thoracic expansion. Furthermore, singing does not require a device or an assistant, and can provide some necessary enjoyment to reduce treatment burden and reinforce further training (Raskin 2009).

A singing intervention can be carried out in a one-to-one or in a group setting, and should be conducted in a non-judgmental and supportive environment. The program needs to be of sufficient length and intensity to allow participants to master the diaphragmatic breathing technique. This can vary from individual to individual, depending on their age, background, illness severity, past experience with singing and music as well as the relationship between the singing facilitator and the patient. A study of people with emphysema (over 60 years of age) indicated that at least two half-hour sessions are necessary for participants to learn the diaphragmatic breathing method correctly (Engen 2005).

\section{Why it is important to do this review}

A recent Cochrane systematic review identified very few research studies on non-medical interventions in the field of CF (Glasscoe 2008). Despite progress in medical treatment for CF, psychological therapies to improve emotional well-being have been limited (Elgudin 2004). To date, CF treatment has been dominated by rigorous medical treatments. Although essential, this may also reflect a disease-oriented view, in which only the physical symptoms are treated. A single medical treatment may be unable to provide the care and management required to improve all aspects of QoL in people living with CF. A multidisciplinary treatment regimen may be effective in meeting the complex needs of individuals with CF. Research in health psychology supports this view and provides strong evidence that numerous factors influence both illness and well-being (Bernard 1994; Knight 1998). These 
should be taken into account when providing a health service which aims to optimise both medical and psycho-social health outcomes.

Singing is a relatively inexpensive adjunct intervention which can potentially enhance $\mathrm{Q} O \mathrm{~L}$ and provide enjoyable and effective exercise for the respiratory system of people with CF.

This is an update of previous versions of this review (Irons 2010; Irons 2014).

\section{O B JE C T IVES}

To evaluate the effects of singing as an adjunct therapy to standard treatment on QoL, respiratory muscle strength, pulmonary function and morbidity of children and adults with CF.

\section{METHODS}

\section{Criteria for considering studies for this review}

\section{Types of studies}

Randomised or quasi-randomised controlled trials.

\section{Types of participants}

People with CF, of any age, diagnosed on the basis of sweat testing or genotype analysis.

\section{Types of interventions}

All types of singing intervention that included diaphragmatic breathing, which were carried out in a group or one-to-one setting, facilitated by singing instructors or teachers, voice coaches or trainers, or music therapists, for a minimum of two half-hour sessions. Studies comparing singing with a control group that did not involve the activation of the respiratory muscles were to be considered (for example, playing computer games or doing craft activities). Studies using non face-to-face delivery format, such as DVD or CD were not considered as these formats could not address some important issues such as how to use the voice in a healthy way while singing, and to obtain immediate feedback on singing practice, posture and breathing technique. Further, individual or group singing sessions can also be adjusted to the levels of singers, which is hard to achieve through media, such as DVD or CD.

\section{Types of outcome measures}

\section{Primary outcomes}

1. QoL measured by validated instruments, e.g. Cystic Fibrosis Questionnaire-Revised (CFQ-R) (Quittner 2009), St. George's Respiratory Questionnaire (Jones 1991), Pediatric Quality of Life Inventory TM (PedsQLTM) (Varni 1999)

2. Respiratory muscle function
a. maximal inspiratory pressure (MIP)
b. maximal expiratory pressure (MEP)
c. cough peak flow (Table 1)

\section{Secondary outcomes}

1. Other subjective scores (e.g. cough diary using Likert scales or visual analogue scales (Table 1) measuring subjective assessment of interference of cough)
2. Spirometry
a. forced expiratory volume in one second $\left(\mathrm{FEV}_{1}\right)$
b. forced vital capacity (FVC)
c. forced mid-expiratory flow rate $\left(\mathrm{FEF}_{25-75 \%}\right)$

3. Number of participants experiencing adverse effects (e.g. coughing up blood and difficulty in breathing)

4. Respiratory exacerbations

a. total number of hospitalised days

b. total number of symptomatic days

c. number of participants with respiratory exacerbations

5. Adherence to other CF treatments (e.g. measured by a diary, selfevaluation checklist)

6. Psychological assessments measuring self-efficacy, depression and anxiety

\section{Search methods for identification of studies}

There were no language or publication restrictions.

\section{Electronic searches}

We searched the Group's Cystic Fibrosis Trials Register for relevant trials using the terms: 'cystic fibrosis' AND 'singing'.

The Cystic Fibrosis Trials Register is compiled from electronic searches of the Cochrane Central Register of Controlled Trials (CENTRAL) (updated each new issue of The Cochrane Library), quarterly searches of MEDLINE, a search of Embase to 1995 and the prospective handsearching of two journals - Pediatric Pulmonology and the Journal of Cystic Fibrosis. Unpublished work is identified by searching the abstract books of three major cystic fibrosis conferences: the International Cystic Fibrosis Conference; the European Cystic Fibrosis Conference and the North American Cystic Fibrosis Conference. For full details of all searching activities for the register, please see the relevant sections of the website.

Date of search: 07 January 2019.

We also searched the following sources; please see the appendices for details of search terms and dates:

- Allied and Complementary Database AMED (1985 to 2019) (Appendix 1);

- PsycINFO (1872 to 2019) (Appendix 2);

- CINAHL (all years to present) (Appendix 3);

- Dissertation Abstracts International (late 1960 to 2019) (Appendix 4);

- www.clinicaltrials.gov (all years to 2019) (Appendix 5);

- Music therapy research database (all years to 24/09/2009) (Appendix 6);

- National Research Register (NRR) Archive (2000 to 2012) (Appendix 7).

Note: the Music Therapy Research Database and the National Research Register (NRR) Archive are inactive and have not been searched for recent updates.

\section{Searching other resources}

We searched other relevant publications, including hand searching of music or singing or music therapy journals (Table 2). Date of latest search: 28 March 2019. 
Further, we have contacted experts (singing or music therapyrelated researchers and singing facilitators or teachers) in this area and on receipt of written communication from the authors of trials, would have included these in the review as necessary.

\section{Data collection and analysis}

\section{Selection of studies}

Two authors (JYI, AC) independently assessed studies for inclusion in the review based on the inclusion criteria stated above. If there was any disagreement in this process, they would have consulted with the third author (DK) and resolved by discussion.

\section{Data extraction and management}

Two authors (JYI, AC) independently extracted data from the eligible study on to a standard data extraction form. One author (JYI) entered the data into RevMan for analysis (RevMan 2011) and $\mathrm{AC}$ checked the entered data.

The authors reviewed the study that satisfied the inclusion criteria and recorded the following information: study setting, year of study, source of funding, participants recruitment details (including number of eligible people), inclusion and exclusion criteria, other symptoms, randomisation and allocation concealment method, numbers of participants randomised, blinding (masking) of participants, care providers and outcome assessors, duration of intervention, previous singing training, co-interventions, numbers of participants not followed up, reasons for withdrawals from study protocol (clinical, side-effects, refusal and other), details on sideeffects of therapy, and whether intention-to-treat analyses were conducted. The authors extracted data on the outcomes described previously at three points: short term (at less than one month), medium term (over one month and up to six months), and longer term (over six months and up to one year and annually thereafter). If in future updates of this review, the authors include further studies and if necessary, they planned to contact the study authors for any missing information.

In a post hoc change, the authors considered that reporting the differences (change scores) from baseline to post-intervention or follow up, or both, in the outcome measures to be appropriate in this review.

\section{Assessment of risk of bias in included studies}

One review author (PP) and a member of the CFGD editorial base independently assessed the risk of bias of the included study using the 'Risk of Bias' tool as described in Chapter 8 of the Cochrane Handbook for Systematic Reviews of Interventions (Higgins 2011).

\section{Generation of the allocation sequence}

They assessed the study for the generation of allocation sequence as follows:

1. low risk of bias, if methods of randomisation include using a random number table, computer-generated lists or similar methods;

2. unclear risk of bias, if the trial was described as randomised, but no description of the methods used to allocate participants to treatment group was described;

3. high risk of bias, if methods of randomisation include alternation, the use of case record numbers, dates of birth or day of the week, and any procedure that was entirely transparent before allocation.

\section{Allocation concealment}

They assessed whether allocation was adequately concealed, to prevent both participants and investigators from foreseeing assignment:

1. low risk of bias, if the allocation of participants involved a central independent unit, on-site locked computer, identically appearing numbered drug bottles or containers prepared by an independent pharmacist or investigator, or sealed opaque envelopes;

2. unclear risk of bias, if the method used to conceal the allocation was not described;

3. high risk of bias, if the allocation sequence was known to the investigators who assigned participants, for example it was based on day of admission or case record number.

\section{Blinding (or masking)}

Due to the nature of the intervention, it is impossible to blind participants. They assessed the included study as to whether the outcome assessors were blinded to treatment allocation (low risk of bias); unclear whether they were blinded (unclear risk of bias); or not blinded to treatment (high risk of bias).

\section{Follow-up}

They graded the study as to whether numbers of and reasons for dropouts and withdrawals in all intervention groups were described; or whether it was specified that there were no dropouts or withdrawals:

1. low risk of bias, if reasons for dropouts and withdrawals described;

2. unclear risk of bias, if insufficient or selective reporting of dropouts and withdrawals;

3. high risk of bias, if not reporting reasons for dropouts and withdrawals likely to be related to true outcome.

\section{Selective outcome reporting}

They tried to identify and report on any selective reporting in the included study, by comparing the study protocol with the final published paper. If in future the authors include further studies, for which the protocols are not available, the authors will compare the 'Methods' and 'Results' sections of the published study. Authors will make risk of bias judgements as follows:

1. low risk of bias, if all outcomes reported as being measured were reported;

2. unclear risk of bias, if it was unclear whether all measured outcomes were reported;

3. high risk of bias, if not all outcomes that were measured were reported.

\section{Other potential sources of bias}

They tried to identify any other sources of bias not reported elsewhere in the review and assessed their potential for putting the study results at risk of bias. 


\section{Measures of treatment effect}

If the authors had identified more than one study, they would have undertaken an initial qualitative comparison of all the individually analysed studies to examine whether pooling of results (metaanalysis) was reasonable. This would have taken into account differences in study populations, inclusion and exclusion criteria, interventions and outcome assessment. The results from studies that met the inclusion criteria and that report any of the outcomes of interest would have been included in the subsequent metaanalyses.

For the dichotomous outcome variables of each individual study, the authors planned to calculate the odds ratio (OR) and 95\% confidence intervals $(\mathrm{Cls})$ using intention to treat analysis. The authors used the Cochrane statistical package RevMan 5.1 (RevMan 2011). If the authors include more studies in future, they will calculate the numbers needed to treat (NNT) from the pooled OR and its $95 \% \mathrm{Cl}$ applied to a specified baseline risk (from the control group) using an online calculator (Cates 2003).

For continuous outcomes, the authors calculated the mean difference (MD) and 95\% Cls using RevMan 5.1 (RevMan 2011) using 'as treated' approach. If, in future, studies report outcomes using different measurement scales, the authors will calculate the standardised mean difference.

\section{Unit of analysis issues}

Cross-over trials are not appropriate for this intervention and thus the authors planned to only include data from the first arm of any cross-over studies.

\section{Dealing with missing data}

The authors would have requested further information from the primary investigators where appropriate.

\section{Assessment of heterogeneity}

If more than one study were available, the authors planned to describe heterogeneity between the study results and test this to see if it reached statistical significance using the chi ${ }^{2}$ test. The authors would have considered heterogeneity to be significant if the $P$ value was less than 0.10 (Higgins 2011). The authors also planned to present the $I^{2}$ statistic, which quantifies the inconsistency of the results of the studies as described in Chapter 9 of the Cochrane Handbook for Systematic Reviews of Interventions (Higgins 2011), and would have defined heterogeneity as low if less than $25 \%$, moderate if the value was between $25 \%$ and $75 \%$, and high if the value was over 75\% (Higgins 2003).

\section{Assessment of reporting biases}

If the combination of data and a meta-analysis (with at least 10 studies) had been possible, the authors would have assessed publication bias using a funnel plot.

\section{Data synthesis}

The authors calculated the summary OR and mean differences with $95 \% \mathrm{Cls}$ using a fixed-effect model. They would have used a random-effects model if they had concerns about statistical heterogeneity, i.e. when there was at least moderate heterogeneity as defined above using the $\mathrm{I}^{2}$ statistic, where $\mathrm{I}^{2}$ is at least $50 \%$.

The authors planned only to combine 'Other subjective scores' (see Secondary outcomes), if they deemed it clinically appropriate.

\section{Subgroup analysis and investigation of heterogeneity}

If the authors had been able to include sufficient studies in the review and it was appropriate, they planned the following a priori sub-group analyses:

1. children (under 18 years old) versus adults;

2. severity of CF (based on $\mathrm{FEV}_{1} \%$ predicted, where over $80 \%$ is classified as mild; $50 \%$ to $79 \%$ is classified as moderate; $30 \%$ to $49 \%$ is classified as severe; and less than $30 \%$ is classified as very severe);

3. type of singing intervention (e.g. individual or group singing, length of follow up);

4. intervention conducted during an acute exacerbation versus stable state.

\section{Sensitivity analysis}

The authors also planned sensitivity analyses to assess the impact of the potentially important factors on the overall outcomes, if there were sufficient studies $(n=10)$ :

1. variation in the inclusion criteria (e.g. studies conducted during exacerbations versus stable state, duration of intervention);

2. risk of bias in the included studies (selection, performance, detection, attrition and reporting bias);

3. analysis using random-effects model (to assess heterogeneity).

\section{RE S U L T S}

\section{Description of studies}

\section{Results of the search}

A total of 510 records to potential studies were identified in the searches; after duplicates were removed there were 327 unique records for screening. Two authors (JYI and AC) undertook initial screening of the abstracts of these records; a total of 19 papers and one trial registry entry were further reviewed for detailed assessment. Of these, only one study (two records) fulfilled the inclusion criteria; hence in the current review 18 studies (each with a single record) are listed in the table 'Characteristics of excluded studies' and one study is included (Irons 2012). A study flow diagram is shown in the figures (Figure 1). 
Figure 1. Study flow diagram.

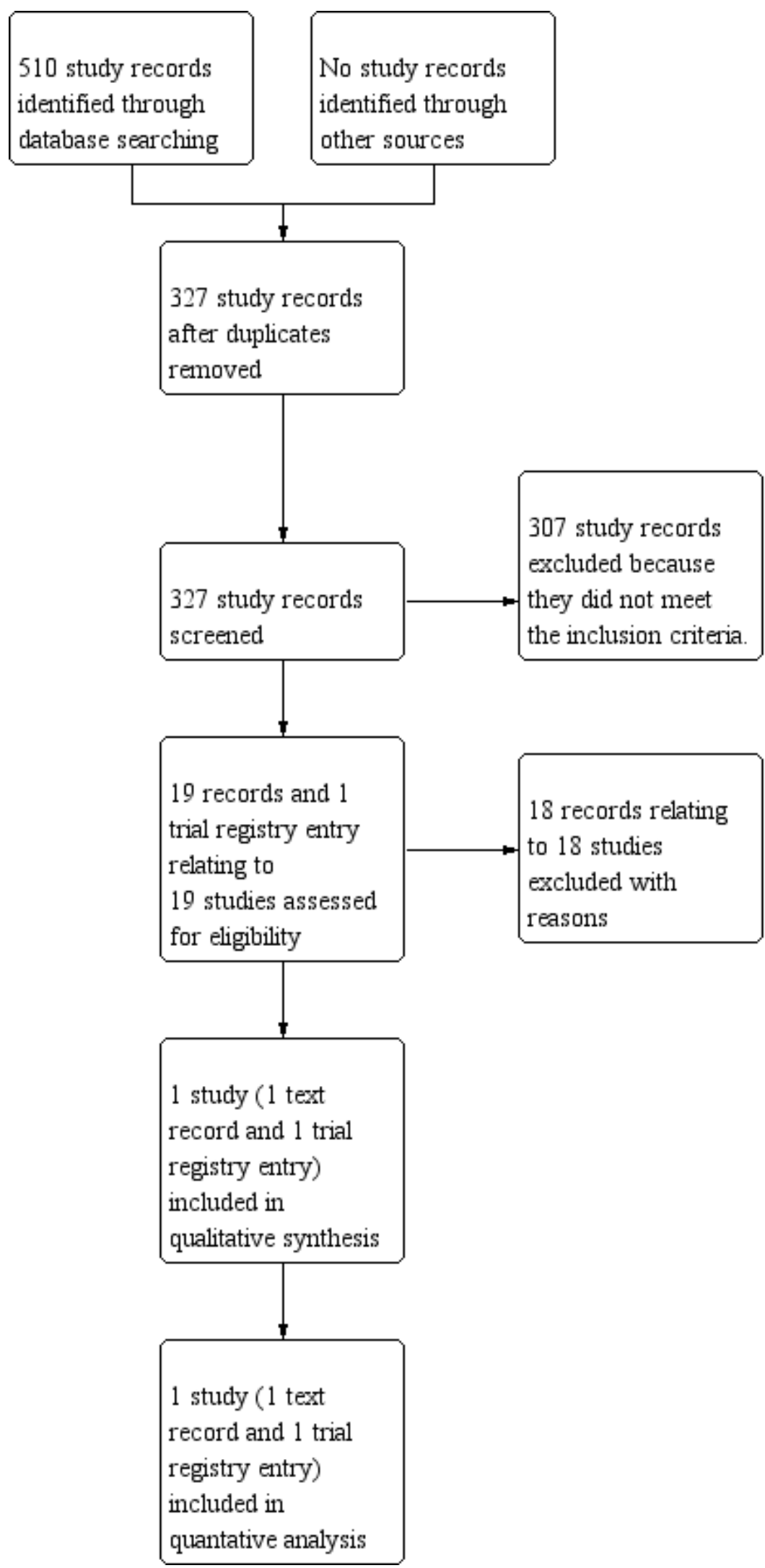




\section{Included studies}

The included study was a dual-centre (both in Australia), parallel, randomised controlled study, which included hospitalised children and adolescents (aged 7 to 17 years) with a pulmonary exacerbation (Irons 2012). A total of 51 young people were randomly assigned to either a singing group or a control group participating in nonphysical recreational activities. The singing group participated in eight individual singing lessons during hospitalisation over a period of approximately two weeks; these lessons consisted of:

1. exercises to develop the desired posture for singing;

2. diaphragmatic breathing exercises;

3. vocal warm-ups; and

4. singing using the diaphragmatic technique.

Children in the control group participated in their preferred non-physical recreational activities (e.g. playing computer games or watching movies) for the same period of time. Outcome measures included CFQ-R (QOL), MIP, MEP and spirometry $\left(\mathrm{FEV}_{1}, \mathrm{FVC}, \mathrm{FEF}_{25-75 \%}\right)$. These were reported at post-intervention (approximately two weeks from baseline) and follow up (six to eight weeks post-intervention). In addition, for the post-intervention period a singing diary, which consisted of six simple daily tasks for six weeks, was given to the participants in the singing group only in order to encourage their singing activities at home. The participants of the control group were encouraged to perform their usual CF management at home.

Only 40 participants (20 for each group) were included in analysis at post-intervention and 30 (15 for each group) at follow up.

\section{Excluded studies}

A total of 18 studies were excluded (Calik-Kutukcu 2016; Chung 2011; Frias 2018; Goldbeck 2014; Goldenberg 2012; Goldenberg 2018; Grasso 2000; Grossoehme 2014; Irons 2014; Kaak 2011; Kamioka 2014; Kemper 2005; Main 2005; Moola 2012; Mrazova 2010; Reichardt 2011; Roux 2007; Whitehead 2018).
Two singing studies were excluded due to design: one was a collective case study; and the second was a scoping review paper (Goldenberg 2012; Goldenberg 2018). A further qualitative study explored young people's perceptions towards physical activities (Moola 2012). Five studies were excluded as they were systematic review papers (Goldbeck 2014; Kamioka 2014; Main 2005; Mrazova 2010; Whitehead 2018).

Three studies were excluded as the participants did not have CF (Grossoehme 2014; Irons 2014; Reichardt 2011). One study enrolled parents of children with CF to examine how they used spirituality to deal with stress; singing was not explored (Grossoehme 2014). One was a qualitative singing study where young people with CF were excluded (Irons 2014). The third study reported the benefits of a singing program (Hustife ${ }^{\circledR}$ - Brummer $^{\oplus}$ ) based on observations; however the program was designed for people with chronic obstructive pulmonary disease and not CF (Reichardt 2011).

One study used pre-recorded music as an adjunct to regular chest physiotherapy for toddlers with CF (under 24 months old) and their caregivers; however, singing was not explored in this study (Grasso 2000). A further study investigated the effects of listening to Bach's Magnificat (a religious choral work) on 40 adults with pneumonia or acute bronchitis; again singing (as opposed to listening to music) was not part of the intervention in this study (Roux 2007). Three further studies also investigated the benefits of listening to music (Calik-Kutukcu 2016; Frias 2018; Kemper 2005). One German study was excluded as it investigated the effects of playing the didgeridoo (as opposed to singing) with people with CF (Kaak 2011). Finally, one paper discussed complementary and alternative therapies for children with a respiratory condition (Chung 2011).

\section{Risk of bias in included studies}

An overview of our judgement of the risk of bias in the included study is presented in the figures (Figure 2). 
Figure 2. Risk of bias summary: review authors' judgements about each risk of bias item for each included study.

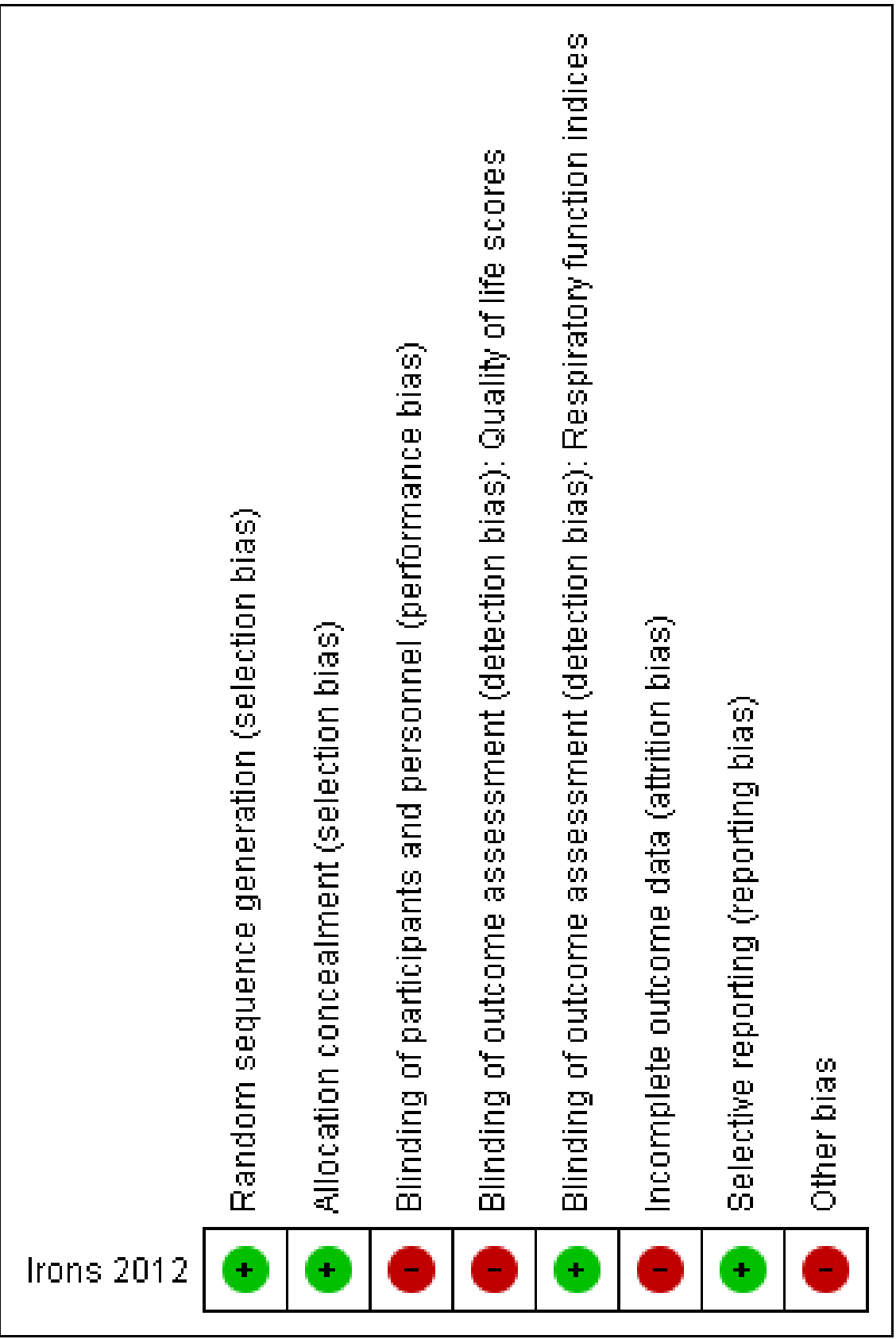

\section{Allocation}

The randomisation sequence was computer-generated by a person external to the study; thus there is a low risk of bias (Irons 2012). Allocation was concealed by using opaque stickers on a randomisation list, and again the risk of bias is low (Irons 2012).

\section{Blinding}

Due to the nature of intervention, blinding was not possible for either participants or clinicians, leading to a high risk of bias. In addition, the researcher who collected the QoL data was not blinded to the intervention allocation, leading to a high risk of bias for these outcomes. However, the respiratory scientists who collected data for all lung function tests were blinded to participants' allocation. This factor gave a low risk of bias due to blinding for outcome assessors for these outcomes (Irons 2012).

\section{Incomplete outcome data}

The attrition rate was high, which may represent a bias; however, there were similar dropout rates in both groups (Irons 2012). The authors judged there to be an high risk of bias for this domain.

\section{Selective reporting}

The study was considered at low risk of bias for reporting bias. The study reported all outcomes according to their protocol in line with the record on the Australian New Zealand Clinical Trials 
Registry. The authors also reported all time-points (baseline, postintervention, follow up) as planned (Irons 2012).

\section{Other potential sources of bias}

There may have been a selection bias, as people with a previous positive experience of singing may have been more likely to agree to enrol in a singing study (high risk of bias).

The paper did not report the sample size calculation. Study authors reported that the calculation was based on power of $90 \%$ (at $5 \%$ significance) for a MD (standard deviation (SD)) of 10 (10) $\mathrm{cm} \mathrm{H}_{2} \mathrm{O}$ in MIP between groups (Irons 2012). This estimated a required sample size of 23 participants per group.

\section{Effects of interventions}

\section{Primary outcomes}

\section{QoL}

There were no significant differences between the two groups at either post-intervention or follow up. Although there were some within-group statistically significant increases in some domains for treatment and control groups (e.g. emotional, social and vitality) between baseline and post-intervention assessment, as presented in the additional tables (Table 3).

Investigators assessed QoL using the CFQ-R questionnaire which has 12 different domains, some of which apply only for adolescents (from 14 years of age) (Quittner 2009). The data from 40 participants in these 12 domains were partially skewed, and thus nonparametric tests (Wilcoxon signed-rank) were performed for the original analysis. We present medians and IQR at baseline, postintervention and follow up in the additional tables (Table 3), since it would be inappropriate to analyse the means and SD of the QoL data from the included study (Irons 2012). Post-intervention assessment took place after eight sessions (i.e. on average, between 10 and 14 days from baseline). Follow-up assessment took place six to eight weeks after the post-intervention time-point. There were 40 participants included in the analysis from baseline to post-intervention, while 30 were included for follow-up analysis. Four domains (vitality, health perception, role and weight) apply only for adolescents (between 14 and 17 years of age). For these domains, data from six adolescents from each group were included for the post-intervention analysis and from five adolescents for the follow-up analysis.

\section{Respiratory muscle function}

\section{a. MIP}

There were no statistically significant differences between the singing and control groups at either post-intervention, MD 6.00 (95\% Cl-1.67 to 13.67$)$; or follow up, MD 4.40 (95\% Cl -9.36 to 18.16$)$ (Analysis 1.1).

\section{b. MEP}

There were no statistically significant differences between the singing and control groups at post-intervention, MD 3.05 (95\% $\mathrm{Cl}-12.43$ to 18.53$)$. However, statistical significance in the mean difference was detected at follow up favouring the singing group, MD 25.80 (95\% Cl 5.94 to 45.66) (Analysis 1.2).

\section{c. Cough peak flow}

This outcome was not reported.

\section{Secondary outcomes}

\section{Other subjective scores}

Other subjective scores (e.g. cough diary using Likert scales or visual analogue scales measuring subjective assessment of interference of cough) were not reported.

\section{Spirometry \\ a. FEV $_{1}$}

There were no statistically significant differences between the two groups at either post-intervention, MD $-0.04(95 \% \mathrm{Cl}-0.20$ to 0.11$)$; or follow up, MD -0.15 ( $95 \% \mathrm{Cl}-0.36$ to 0.06$)$ (Analysis 1.3).

\section{b. FVC}

There were no statistically significant differences between the two groups at either post-intervention, MD $-0.10(95 \% \mathrm{Cl}-0.25$ to 0.06$)$; or follow up, MD -0.11 ( $95 \% \mathrm{Cl}-0.29$ to 0.07 ) (Analysis 1.4).

C. $\mathrm{FEF}_{\mathbf{2 5}-\mathbf{7 5} \%}$

There were no statistically significant differences between the two groups at either post-intervention, $\mathrm{MD}-0.03(95 \% \mathrm{Cl}-0.39$ to 0.33$)$; or follow up, MD -0.29 ( $95 \% \mathrm{Cl}-0.81$ to 0.24 ) (Analysis 1.5).

\section{Number of participants experiencing adverse effects}

Irons reported that no adverse effects were observed in the singing group; adverse events for the control group were not reported in the paper.

\section{Respiratory exacerbations \\ a. total number of hospitalised days}

This outcome was not reported.

\section{b. total number of symptomatic days}

This outcome was not reported.

c. number of participants with respiratory exacerbations

This outcome was not reported.

\section{Adherence to other CF treatments}

This outcome was not reported.

\section{Psychological assessments measuring self-efficacy, depression and anxiety}

This outcome was not reported.

\section{DISCUSSION}

\section{Summary of main results}

In this update, only one small study conducted by three of the review authors has been included (Irons 2012). At follow up, a statistically significant improvement in MEP favouring the singing group was found, MD 25.80 ( $95 \% \mathrm{Cl} 5.94$ to 45.66); however there were no differences in other lung function parameters and both groups experienced improvements in a number of QoL domains. At follow up, only the singing group continued with any form of 
the intervention; although singing sessions did not continue as they had in the hospital, participants were asked to keep a diary of six simple singing tasks for six to eight weeks following hospital discharge.

\section{Overall completeness and applicability of evidence}

There is insufficient evidence to make a judgement on the efficacy of singing for people with CF. The single included study was limited by the small sample size, high attrition rate and the limited applicability of MIP and MEP (Irons 2012). There is no guideline on the minimal clinically important difference in MIP and MEP for children and adolescents with CF; and the normal range of MIP and MEP is reported to be wide (Domenech-Clar 2003). Therefore, the result should be interpreted with caution.

\section{Quality of the evidence}

The quality of the evidence is currently low due to the small sample size, high attrition rate of participants and the non-blinded assessment of QoL measures.

\section{Potential biases in the review process}

The authors sought to limit potential biases through extensive searches and attempts to identify all relevant studies. As already declared in the protocol, authors of the included study are also three of the authors of this review; therefore to minimise any bias, risk of bias assessments of the included study were conducted by the fourth review author and a member of the editorial base.

\section{Agreements and disagreements with other studies or reviews}

The results of the included study (Irons 2012) were similar to those of previous singing studies in other chronic respiratory conditions (Bonilha 2009; Lord 2010), in multiple sclerosis (MS) (Wiens 1999) and in Parkinson's Disease (Di Benedetto 2009). While $\mathrm{CF}$ is a different condition to these other chronic illnesses, there are similarities with regard to the disease impact on QoL, the characteristics of the obstructive lung disease, the respiratory symptoms (difficulty in breathing, breathlessness), and the nature of the chronic conditions. For example, patients with chronic obstructive pulmonary disorder (COPD) demonstrated increased respiratory muscle strength measured by MEP (mean change from baseline to post-intervention $3.0 \mathrm{H}_{2} \mathrm{O} \mathrm{cm} ; \mathrm{P}=0.05$ ) after 24 weekly singing sessions (Bonilha 2009). Another study in patients with COPD found that 12 bi-weekly group singing sessions reduced anxiety and depression and enhanced general well-being (Lord 2010). Also, a 12-week singing intervention in patients with MS improved MEP (mean change from baseline to post-intervention 2.8 $\mathrm{H}_{2} \mathrm{O} \mathrm{cm} ; \mathrm{P}>0.05$ ) (Wiens 1999), and a 13-week singing program in people with Parkinson's Disease helped to improve MIP (mean change from baseline to post-intervention $7.4 \mathrm{H}_{2} \mathrm{O} \mathrm{cm} ; \mathrm{P}=0.02$ ) and MEP (mean change from baseline to post-intervention $21 \mathrm{H}_{2} \mathrm{O} \mathrm{cm}$; $P=0.01$ ) (Di Benedetto 2009).

The included study demonstrated a mean (SD) improvement of 12.1 (7.8) $\mathrm{H}_{2} \mathrm{O} \mathrm{cm}$ in MIP scores from baseline to post-intervention in the singing group; the mean (SD) increase of 6.1 (14.5) $\mathrm{H}_{2} \mathrm{O} \mathrm{cm}$ seen in the control arm was less, but the difference between groups was not statistically significant (Irons 2012). Neverthless, the increase in MIP in the included study was a greater improvement than in other studies on singing as an intervention (Bonilha 2009; Di Benedetto 2009; Wiens 1999), although the numbers cannot be compared directly given the differences between other conditions (COPD, Parkinson's Disease and MS) and CF. The magnitude of the increase in MIP in the Irons study is similar to that seen with a conventional inspiratory muscle training method for 10 weeks during a stable period, a study of which reported an increase in mean MIP postintervention of $14 \mathrm{H}_{2} \mathrm{O} \mathrm{cm}$ (Sawyer 1993).

In relation to the QoL results from the Irons study, participants in both the singing and control groups showed similar improvements in respiratory symptoms and treatment burden domains at postintervention (Irons 2012). Only the singing group continued to have a reduced treatment burden at follow up as they had continued their singing activities at home after discharge. In addition, the control group improved in the social and vitality domains, and the singing group in the emotional and digestion domains of the CFQR. Both groups' improvements in some QoL domains may be due to the standard medical treatment they received as inpatients or the fact that they were discharged from hospital, or a combination of both. It was not possible for this study design to assess the impact of singing independent of this standard treatment. In summary, without sufficient data, the effect of a singing intervention on QoL for people with CF cannot be confirmed and more studies are needed to assess possible health benefits, in light of other studies which have indicated a positive impact of singing on QoL (Bonilha 2009; Engen 2005; Kenny 2004; Lord 2010; Lord 2012; Unwin 2002; Wiens 1999).

\section{AUTHORS' CONCLUSIONS}

\section{Implications for practice}

There is insufficient evidence to recommend singing as an effective adjunct treatment in individuals with cystic fibrosis (CF). However, people with $\mathrm{CF}$ who enjoy singing should be encouraged to do so. There is growing interest in non-medical treatments for CF, and more research into these treatments, including singing, is needed to inform health practitioners, people with $\mathrm{CF}$ and their families (Butler 2012).

\section{Implications for research}

Adequately-powered and carefully-designed research studies are needed. The design of future randomised controlled trials should take account of CF severity (mild, moderate and severe), and include detailed information about the singing intervention (vocal exercises, song type, pitch and dynamic range); delivery format (individual or group); length and frequency of sessions and prescribed singing practice time. Future studies could also take account of participants' previous experience with singing. Trials evaluating short-term (acute admission, up to one month), medium-term (over one month and up to six months) and longerterm outcomes (over six months and up to one year and annually thereafter) are also required. Future studies could also address the effects of singing for people with advanced CF in relation to quality of life.

\section{ACKNOWLEDGEMENTS}

The review authors wish to thank Nikki Jahnke and the Cochrane Cystic Fibrosis and Genetic Disorders Review Group for their support. 
This project was supported by the National Institute for Health Research, via Cochrane Infrastructure funding to the Cochrane Cystic Fibrosis and Genetic Disorders Group. The views and opinions expressed therein are those of the authors and do not necessarily reflect those of the Systematic Reviews Programme, NIHR, NHS or the Department of Health. 


\section{REFERE N CES}

\section{References to studies included in this review}

Irons 2012 \{published and unpublished data\}

Irons JY, Kenny D, Chang AB. Let's Sing Out!: The effects of singing on quality of life and lung function of children and adolescents with cystic fibrosis. ACTRN12609000471280. www.anzctr.org.au/Trial/Registration/TrialReview.aspx? ID=83944 (accessed 28 May 2013).

Irons JY, Kenny DT, McElrea M, Chang AB. Singing therapy for young people with cystic fibrosis - a randomized controlled pilot study. Music and Medicine 2012;4(3):136-45. [ACTRN: 12609000471280; CFGD Register: PE185]

\section{References to studies excluded from this review}

\section{Calik-Kutukcu 2016 \{published data only\}}

Calik-Kutukcu E, Saglam M, Vardar-Yagli N, Cakmak A, InalInce D, Bozdemir-Ozel C, et al. Listening to motivational music while walking elicits more positive affective response in patients with cystic fibrosis. Complementary Therapies in Clinical Practice 2016;23:52-8. [DOI: 10.1016/j.ctcp.2016.03.002]

\section{Chung 2011 \{published data only\}}

Chung Y, Dumont RC. Complementary and alternative therapies: Use in pediatric pulmonary medicine. Pediatric Pulmonology 2011;46(6):530-44.

\section{Frias 2018 \{published data only\}}

Frias JP, Montero-Ruiz A, Galvez LA, Perez-Ruiz E, Huelamo MP, Martin-Montañez E. A music therapy intervention as an adjunct to chest physiotherapy in children with cystic fibrosis. European Respiratory Journal 2018;52(Suppl 62):PA4626.

\section{Goldbeck 2014 \{published data only\}}

Goldbeck L, Fidika A, Herle M, Quittner AL. Psychological interventions for individuals with cystic fibrosis and their families. Cochrane Database of Systematic Reviews 2014, Issue 6. [DOI: 10.1002/14651858.CD003148.pub3]

\section{Goldenberg 2012 \{unpublished data only\}}

Goldenberg RB. Singing and cystic fibrosis: a collective case study on the effects of private voice lessons on the pulmonary function and quality of life of adult cystic fibrosis patients. Thesis 2012.

\section{Goldenberg 2018 \{published data only\}}

Goldenberg RB. Singing lessons for respiratory health: a literature review. Journal of Voice 2018;32(1):85-94.

\section{Grasso 2000 \{published data only\}}

Grasso MC, Button BM, Allison DJ, Sawyer SM. Benefits of music therapy as an adjunct to chest physiotherapy in infants and toddlers with cystic fibrosis. Pediatric Pulmonology 2000;29:371-81.
Grossoehme 2014 \{published data only\}

Grossoehme DH, Szczesniak R, Dodd C, Opipari-Arrigan L. Dyadic adjustment and spiritual activities in parents of children with cystic fibrosis. Religions 2014;5(2):385-401.

Irons 2014 \{published data only\}

Irons JY, Kuipers K, Petocz P. Exploring the health benefits of signing for young people with cystic fibrosis. Internatioanl Journal of Therapy and Rehabilitation 2014;20(3):144-53. [DOI: 10/12968/ijtr.2013.20.3.144]

Kaak 2011 \{published data only\}

Kaak I, Helbig I, Ankermann T. Didgeridoo playing as an adjunctive therapy to conventional physiotherapy for patients with cystic fibrosis [Didgeridoospielen als Ergänzung zur konventionellen Physiotherapie bei zystischer fibrose]. pt Zeitschrift für Physiotherapeuten 2011;63(2):6-14.

\section{Kamioka 2014 \{published data only\}}

Kamioka H, Tsutani K, Yamada M, Park H, Okuizumi H, Tsuruoka K, et al. Effectiveness of music therapy: a summary of systematic reviews based on randomized controlled trials of music interventions. Patient Preference and Adherence 2014;8:727-54.

\section{Kemper 2005 \{published data only\}}

Kemper KJ, Daunhauer SC. Music as therapy. Southern Medical Association 2005;98(3):282-8.

\section{Main 2005 \{published data only\}}

Main E, Prasad A, van der Schans CP. Conventional chest physiotherapy compared to other airway clearance techniques for cystic fibrosis. Cochrane Database of Systematic Reviews 2005, Issue 1. [DOI: 10.1002/14651858.CD002011.pub2]

Moola 2012 \{published data only\}

Moola FJ, Faulkner GE, Schneiderman JE. "No time to play": Perceptions toward physical activity in youth with cystic fibrosis. Adapted Physical Activity Quarterly 2012;29(1):44-62.

\section{Mrazova 2010 \{published data only\}}

Mrazova M, Celec P. A systematic review of randomized controlled trials using music therapy for children. Journal of Alternative and Complementary Medicine 2010;16(10):1089-95.

Reichardt 2011 \{published data only\}

Reichardt H. Severe COPD: can singing provide joyful (self) help? Experience with singing therapy (Hustifex ${ }^{\circledR}$ - Brummer $\left.^{\circledR}\right)$ in an acute unit [Schwere COPD: ist freudvolle (Selbst)hilfe durch Singen möglich? (Erfahrungen mit Gesangstherapie (Hustifex ${ }^{\circledR}$ - Brummer ${ }^{\circledR}$ ) in einer Akutklinik)]. Praxis Anthroposophische Medizin Der Merkurstab 2011;5:496-99.

\section{Roux 2007 \{published data only\}}

le Roux FH, Bouic PJD, Bester MM. The effect of Bach's Magnificat on emotions, immune, and endocrine parameters during physiotherapy treatment of patients with infectious lung conditions. Journal of Music Therapy 2007;44(2):156. 
Whitehead 2018 \{published data only\}

Whitehead L, Arabiat RND, Foster M. Singing as an adjunct therapy for children and adults with cystic fibrosis: A Cochrane review summary. International Journal of Nursing Studies 2018;82:163-4. [DOI: 10.1016/j.ijnurstu.2017.09.007]

\section{Additional references}

\section{Bernard 1994}

Bernard LC. Models of Health and Illness. In: Bernard LC, Krupat E editor(s). Health psychology: Biopsychosocial factors in health and illness. Florida: Harcourt Brace Publishers, 1994:3-27.

\section{Bonilha 2009}

Bonilha AG, Onofre F, Vieira ML, Prado MYA, Martinez JAB. Effects of singing classes on pulmonary function and quality of life of COPD patients. International Journal of Chronic Obstructive Pulmonary Disease 2009;4:1-8.

\section{Butler 2012}

Butler CA, Bell SC. Integrative therapies for people with cystic fibrosis. In: Chlan LH, Marshall I editor(s). Integrative Therapies in Lung Health and Sleep. Humana Press, 2012:113-26.

\section{Cates 2003}

Cates C. Visual Rx. Online NNT Calculator. http:// www.nntonline.net/ (accessed 01 May 2013).

\section{Chang 2006}

Chang AB. The physiology of cough. Paediatric Respiratory Reviews 2006;7(1):2-8.

\section{Collyer 2009}

Collyer S, Kenny DT, Archer M. The effect of abdominal directives on breathing patterns in female classical singing. Logopedics, Phoniatrics and Vocology 2009; Vol. 34, issue 3:100-10.

\section{D'Auria 2000}

D'Auria JP, Christian BJ, Henderson ZG, Haynes B. The company they keep: the influence of peer relationships on adjustment to cystic fibrosis during adolescence. Journal of Pediatric Nursing 2000;15(3):175-82.

\section{Di Benedetto 2009}

Di Benedetto P, Cavazzon M, Mondolo F, Rugiu G, Peratoner A, Biasutti E. Voice and choral singing treatment: a new approach for speech and voice disorders in Parkinson's Disease. European Journal of Physical and Rehabilitation Medicine 2009;45(1):13-9.

\section{Domenech-Clar 2003}

Domenech-Clar R, Lopez-Andreu JA, Compte-Torrero L, DiegoDamia A, Macian-Gisbert V, Perpina-Tordera M, et al. Maximal static respiratory pressures in children and adolescents. Pediatric Pulmonology 2003;35(2):126-32.

\section{Elgudin 2004}

Elgudin L, Kishan S, Howe D. Depression in children and adolescents with cystic fibrosis. International Journal of Psychiatry in Medicine 2004;34(4):391-7.

\section{Elliott 2009}

Elliott J. Singing helps my lung problem: Joe Dexter describes his band, Orange, as "Green Day meets The Cure". http:// news.bbc.co.uk/2/hi/8321113.stm (accessed 10 December 2013).

\section{Engen 2005}

Engen R. The singer's breath: implications for treatment of persons with emphysema. Journal of Music Therapy 2005;42(1):20-48.

\section{Enright 2004}

Enright S, Chatham K, Ionescu A A, Unnithan V B, Shale DJ. Inspiratory muscle training improves lung function and exercise capacity in adults with cystic fibrosis. Chest 2004;126(2):405-11.

\section{Fukuda 2000}

Fukuda Y. Breathing training for asthmatic children using music therapy and a survey on patient preference in the training methods. In: Laufer D, Chesky K, Ellis P editor(s). Music as a Human Resource: Drafts and Developments. Berichte über die Tagungen des Arbeitskeises der 'International Society for Music Education' (ISME). Vol. 4, Klön: Verlag Dohr, 1994:149-71.

\section{Glasscoe 2008}

Glasscoe CA, Quittner AL. Psychological interventions for people with cystic fibrosis and their families. Cochrane Database of Systematic Reviews 2008, Issue 3. [DOI: 10.1002/14651858.CD003148.pub2]

\section{Higgins 2003}

Higgins JPT, Thompson SG, Deeks JJ, Altman DG. Measuring inconsistency in meta-analyses. BMJ 2003;327:557-60.

\section{Higgins 2011}

Higgins JP, Green S (editors). Cochrane Handbook for Systematic Reviews of Interventions Version 5.1 [updated March 2011]. The Cochrane Collaboration, 2011. Available from handbook.cochrane.org.

\section{Jones 1991}

Jones PW, Quirk FH, Baveystock CM.

The St George's Respiratory Questionnaire. Respiratory Medicine 1991;85 Suppl B:25-31; discussion 33-7.

\section{Kenny 2004}

Kenny DT, Faunce G. The impact of group singing on mood, coping, and perceived pain in chronic pain patients attending a multidisciplinary pain clinic. Journal of Music Therapy 2004;XLI(3):241-58.

\section{Knight 1998}

Knight SJ. Health psychology and medicine: the art and science of healing. In: Camic PM, Knight SJ editor(s). Clinical Handbook of Health Psychology. Seattle: Hogrefe \& Huber Publishers, 1998:5-15.

\section{Leanderson 1987}

Leanderson R, Sundberg J, von Euler C. Role of diaphragmatic activity during singing. Journal of applied physiology 1987;62(1):259-70. 


\section{Leanderson 1988}

Leanderson R, Sundberg J. Breathing for singing. Journal of Voice 1988;2(1):2-12.

\section{Lipawen 2000}

Lipawen PJ. The effects of harmonica playing on lung function in asthmatic children. Philadelphia, USA: Drexel University, 2000.

\section{Lord 2010}

Lord VM, Cave P, Hume VJ, Evans A, Kelly JL, Polkey M, et al. Singing teaching as a therapy for chronic respiratory disease a randomised controlled trial and qualitative evaluation. $B M C$ Pulmonary Medicine 2010;10:41.

\section{Lord 2012}

Lord VM, Hume VJ, Kelly JL, Cave P, Silver J, Waldman M, et al. Singing classes for chronic obstructive pulmonary disease: A randomized controlled trial. BMC Pulmonary Medicine 2012;12:69. [DOI: 10.1186/1471-2466-12-69]

\section{NHS Choices 2011}

NHS Choices. Cystic fibrosis won't stop me singing. www.nhs.uk/Livewell/women1839/Pages/Cystic-fibrosiscase.aspx. (accessed 10 December 2013).

\section{Nixon 1992}

Nixon PA, Orenstein DM, Kelsey SF, Doershuk CF. The prognostic value of exercise testing in patients with cystic fibrosis. New England Journal of Medicine 1992;327(25):1785-8.

\section{Phelan 1994}

Phelan PD, Olinsky A, Robertson CF. Respiratory illness in children. 4th Edition. Oxford: Blackwell Scientific Publications, 1994.

\section{Quittner 2008}

Quittner AL, Barker DH, Snell C, Grimley ME, Marciel K, Cruz I. Prevalence and impact of depression in cystic fibrosis. Current Opinion in Pulmonary Medicine 2008;14(6):582-8.

\section{Quittner 2009}

Quittner AL, Modi AC, Wainwright C, Otto K, Kirihara J, Montgomery AB. Determination of the minimal clinically important difference scores for the Cystic Fibrosis Questionnaire-Revised respiratory symptom scale in two populations of patients with cystic fibrosis and chronic Pseudomonas aeruginosa airway infection. Chest 2009;135(6):1610-8.

\section{Raskin 2009}

Raskin J, Azoulay, R. Music therapy and integrative pulmonary care. In: Azoulay R, Loewy JV editor(s). Music, the breath and health: advances in integrative music therapy. NY: Satchnote Press, 2009:69-86.

\section{Reid 2008}

Reid WD, Geddes El, O'Brien K, Brooks D, Crowe J. Effects of inspiratory muscle training in cystic fibrosis: A systematic review. Clinical Rehabilitation 2008;22(10-11):1003-13.

\section{RevMan 2011 [Computer program]}

The Nordic Cochrane Centre, The Cochrane Collaboration. Review Manager (RevMan). Version 5.1. Copenhagen: The Nordic Cochrane Centre, The Cochrane Collaboration, 2011.

\section{Robinson 2010}

Robinson KA, Mckoy NA, Saldanha IJ, Odelola OA. Active cycle of breathing technique for cystic fibrosis. Cochrane Database of Systematic Reviews 2010, Issue 11. [DOI: 10.1002/14651858.CD007862.pub2]

\section{Sawyer 1993}

Sawyer EH, Clanton, TL. Improved pulmonary function and exercise tolerance with inspiratory muscle conditioning in children with cystic fibrosis. Chest 1993;104(5):1490-7.

\section{Stacy 2002}

Stacy R, Brittain K, Kerr S. Singing for health: an exploration of the issues. Health Education 2002;102(4):156-62.

\section{Sundberg 1987}

Sundberg J. The science of the singing voice. Northern Illinois University Press, 1987.

\section{Thomasson 1999}

Thomasson M, Sundberg J. Consistency of phonatory breathing patterns in professional operatic singers. Journal of Voice 1999;13(4):529-41.

\section{Titze 1994}

Titze IR. Principles of voice production. Upper Saddle River, NJ: Prentice-Hall Inc, 1994.

\section{Unwin 2002}

Unwin MM, Kenny DT, Davis PJ. The effects of group singing on mood. Psychology of Music 2002;30(2):175-85.

\section{Varni 1999}

Varni JW, Seid M, Rode CA. The PedsQL: measurement model for the pediatric quality of life inventory. Medical Care 1999;37(2):126-9.

\section{Wade 2002}

Wade L. A comparison of the effects of vocal exercises/singing versus music assisted relaxation on peak expiratory flow rates of children with asthma. Music Therapy Perspectives 2002;20:31-7.

\section{Widdicombe 2006}

Widdicombe J, Fontana G. Cough: what's in a name?. European Respiratory Journal 2006;28(1):10-5.

\section{Wiens 1999}

Wiens ME, Reimer MA, Guyn HL. Music therapy as a treatment method for improving respiratory muscle strength in patients with advanced multiple sclerosis. A pilot study. Rehabilitation Nursing 1999;24(2):74-80. 


\section{References to other published versions of this review}

\section{Irons 2010}

Irons JY, Kenny DT, Chang AB. Singing for children and adults with cystic fibrosis. Cochrane Database of Systematic Reviews 2010, Issue 5. [DOI: 10.1002/14651858.CD008036.pub2]

\section{CHARACTERISTICS OF STUDIES}

Characteristics of included studies [ordered by study ID]

\section{Irons 2014}

Irons JY, Petocz P, Kenny DT, Chang AB. Singing as an adjunct therapy for children and adults with cystic fibrosis. Cochrane Database of Systematic Reviews 2014, Issue 6. [DOI: 10.1002/14651858.CD008036.pub3]

Irons 2012

Methods A dual-centre (two paediatric hospitals in Australia), parallel, RCT; singing group versus non-physical recreation group during hospitalisation due to a pulmonary exacerbation; intervention duration approximately 2 weeks. Follow up 6 - 8 weeks post-intervention.

Participants

51 inpatients enrolled (singing group $n=26$; control group $n=25$ ), analysed 40 at post-intervention (singing group $n=20$; control group $n=20$ ) and 30 at follow up (singing group $n=15$; control group $n=$ 15).

Age range: 7 - 17 years; mean (SD) age: singing group $=12.1(3.1)$ years; control group $=11.1(3.7)$ years.

Gender: singing group $=35 \%$ male; control group $=50 \%$ male.

Inclusion criteria: young people with an established diagnosis of CF who were being treated as inpatients for a respiratory exacerbation.

Exclusion criteria: young people who had undertaken individual singing lessons within the past 5 years, who had an intellectual disability or who, according to their treating physician, were too ill to participate in singing activities.

Interventions

Experimental (singing) group: 8 standard individual singing sessions consisting of 4-stage program including posture, diaphragmatic breathing exercise, vocal warm-up and singing favourite songs.

Control group: 8 individual non-physical recreation sessions (e.g. playing computer games, watching movies).

Both groups received intravenous antibiotic treatment and chest physiotherapy as the standard hospital care.

Singing and recreation session facilitator was a qualified, experienced music therapist.

Post-intervention only for the singing group: a singing diary of 6 simple singing tasks for 6 - 8 weeks.

Outcomes

Changes in MIP, MEP, QoL (CFQ-R), and spirometry (FEV 1 , FVC, $\mathrm{FEF}_{25-75 \%}$ ) from baseline to post-intervention, and to follow up ( 6 - 8 weeks post-intervention).

Notes

No adverse events reported. Ethics approvals obtained; informed consent by participants and their parent/caregiver; This study was conducted as a part of the first author's PhD studies and she received a small amount of funding from the University of Sydney for transport and purchasing some equipment through the Post-graduate Research Support Scheme (PRSS) during the data collection period.

\section{Risk of bias}

\begin{tabular}{lll}
\hline Bias & Authors' judgement & Support for judgement \\
\hline $\begin{array}{l}\text { Random sequence genera- } \\
\text { tion (selection bias) }\end{array}$ & Low risk & Sequence was computer-generated by an external person to the study. \\
\hline $\begin{array}{l}\text { Allocation concealment } \\
\text { (selection bias) }\end{array}$ & Low risk & Allocation was concealed by opaque stickers on the randomisation list. \\
\hline \hline
\end{tabular}


Irons 2012 (Continued)

Blinding of participants High risk Participants and clinicians were not blinded due to the nature of the intervenand personnel (perfortion.

mance bias)

All outcomes

\begin{tabular}{|c|c|c|}
\hline $\begin{array}{l}\text { Blinding of outcome as- } \\
\text { sessment (detection bias) } \\
\text { Quality of life scores }\end{array}$ & High risk & $\begin{array}{l}\text { Person who collected the QoL data was not blinded due to the nature of the in- } \\
\text { tervention. }\end{array}$ \\
\hline $\begin{array}{l}\text { Blinding of outcome as- } \\
\text { sessment (detection bias) } \\
\text { Respiratory function in- } \\
\text { dices }\end{array}$ & Low risk & $\begin{array}{l}\text { Respiratory scientists who conducted lung function tests were blinded to the } \\
\text { participants' group allocation. }\end{array}$ \\
\hline $\begin{array}{l}\text { Incomplete outcome data } \\
\text { (attrition bias) } \\
\text { All outcomes }\end{array}$ & High risk & $\begin{array}{l}\text { Attrition rate was relatively high }(21.6 \%) \text {, but similar drop-out rates in both } \\
\text { groups were observed. Reasons for drop-out were stated and similar in both } \\
\text { groups. }\end{array}$ \\
\hline $\begin{array}{l}\text { Selective reporting (re- } \\
\text { porting bias) }\end{array}$ & Low risk & All planned outcome measures were reported at the planned time-points. \\
\hline Other bias & High risk & $\begin{array}{l}\text { Selection bias, as people with a previous positive experience of singing more } \\
\text { likely to agree to enrol in the study. }\end{array}$ \\
\hline
\end{tabular}

CF: cystic fibrosis

CFQ-R: cystic fibrosis questionnaire (revised)

$\mathrm{FEF}_{25-75 \%}$ : mid-expiratory flow

$\mathrm{FEV}_{1}$ : forced expiratory volume at one second

FVC: forced vital capacity

MEP: maximum expiratory pressure

MIP: maximum inspiratory pressure

QoL: quality of life

$\mathrm{RCT}$ : randomised controlled trial

SD: standard deviation

Characteristics of excluded studies [ordered by study ID]

\begin{tabular}{ll}
\hline Study & Reason for exclusion \\
\hline Calik-Kutukcu 2016 & Investigation of the effects of music listening during exercise in people with CF. \\
\hline Chung 2011 & $\begin{array}{l}\text { Not an intervention study, but a summary of complementary and alternative therapies for children } \\
\text { with a respiratory condition. }\end{array}$ \\
\hline Frias 2018 & $\begin{array}{l}\text { Intervention did not include singing, but listening to specially composed music during chest phys- } \\
\text { iotherapy. }\end{array}$ \\
\hline Goldbeck 2014 & A Cochrane Review of psychological interventions for people with CF. \\
\hline Goldenberg 2012 & $\begin{array}{l}\text { Not an RCT, but a collective case study on the effects of voice lessons on pulmonary function and } \\
\text { quality of life in adults with CF. }\end{array}$ \\
\hline Goldenberg 2018 & Not an RCT - a literature review on the benefits of singing. \\
\hline Grasso 2000 & $\begin{array}{l}\text { Intervention is not singing, but using pre-recorded music during daily chest percussion routine } \\
\text { with toddlers. }\end{array}$ \\
\hline \hline
\end{tabular}




\begin{tabular}{|c|c|}
\hline Study & Reason for exclusion \\
\hline Grossoehme 2014 & $\begin{array}{l}\text { Parents of children with CF included looking as using spirituality to deal with stress; singing was } \\
\text { not explored. }\end{array}$ \\
\hline Irons 2014 & A qualitative study, exploring the benefits of singing for children and young people with CF \\
\hline Kaak 2011 & Intervention is not singing, but playing the didgeridoo. \\
\hline Kamioka 2014 & A systematic review of the effects of music therapy interventions. \\
\hline Kemper 2005 & Not an RCT; did not explore singing; did not include people with CF. \\
\hline Main 2005 & A Cochrane Review of physiotherapy for people with CF. \\
\hline Moola 2012 & Qualitative study; did not explore singing. \\
\hline Mrazova 2010 & A systematic review of music therapy for children; not singing. \\
\hline Reichardt 2011 & $\begin{array}{l}\text { People with CF were not included; a observational study on Hustifex }{ }^{\circledR}-\text { Brummer }^{\circledR} \text { - a singing } \\
\text { method specially developed for people with COPD. }\end{array}$ \\
\hline Roux 2007 & Intervention is not singing, but listening to music; people with CF were not included. \\
\hline Whitehead 2018 & A review summary on singing as an adjunct therapy for children and adults with CF. \\
\hline
\end{tabular}

CF: cystic fibrosis

COPD: chronic obstructive pulmonary disorder

$\mathrm{RCT}$ : randomised controlled trial

\section{DATA AND ANALYSES}

\section{Comparison 1. Singing versus control}

\begin{tabular}{|c|c|c|c|c|}
\hline Outcome or subgroup title & No. of studies & $\begin{array}{l}\text { No. of partici- } \\
\text { pants }\end{array}$ & Statistical method & Effect size \\
\hline $\begin{array}{l}1 \text { Change in maximal inspiratory } \\
\text { pressure }\left(\mathrm{cm} \mathrm{H}_{2} \mathrm{O}\right)\end{array}$ & 1 & & $\begin{array}{l}\text { Mean Difference (IV, Fixed, 95\% } \\
\mathrm{CI} \text { ) }\end{array}$ & $\begin{array}{l}\text { Totals not select- } \\
\text { ed }\end{array}$ \\
\hline 1.1 short term (up to 1 month) & 1 & & $\begin{array}{l}\text { Mean Difference (IV, Fixed, 95\% } \\
\text { Cl) }\end{array}$ & $0.0[0.0,0.0]$ \\
\hline $\begin{array}{l}1.2 \text { medium term ( }>1 \text { month and }< \\
6 \text { months) }\end{array}$ & 1 & & $\begin{array}{l}\text { Mean Difference (IV, Fixed, 95\% } \\
\mathrm{CI} \text { ) }\end{array}$ & $0.0[0.0,0.0]$ \\
\hline $\begin{array}{l}2 \text { Change in maximal expiratory } \\
\text { pressure }\left(\mathrm{cm} \mathrm{H}_{2} \mathrm{O}\right)\end{array}$ & 1 & & $\begin{array}{l}\text { Mean Difference (IV, Fixed, 95\% } \\
\mathrm{CI} \text { ) }\end{array}$ & $\begin{array}{l}\text { Totals not select- } \\
\text { ed }\end{array}$ \\
\hline 2.1 short term (up to 1 month) & 1 & & $\begin{array}{l}\text { Mean Difference (IV, Fixed, 95\% } \\
\mathrm{CI})\end{array}$ & $0.0[0.0,0.0]$ \\
\hline $\begin{array}{l}2.2 \text { medium term ( }>1 \text { month and }< \\
6 \text { months) }\end{array}$ & 1 & & $\begin{array}{l}\text { Mean Difference (IV, Fixed, 95\% } \\
\mathrm{CI} \text { ) }\end{array}$ & $0.0[0.0,0.0]$ \\
\hline
\end{tabular}




\begin{tabular}{|c|c|c|c|c|}
\hline Outcome or subgroup title & No. of studies & $\begin{array}{l}\text { No. of partici- } \\
\text { pants }\end{array}$ & Statistical method & Effect size \\
\hline 3 Change in $\mathrm{FEV}_{1}(\mathrm{~L} / \mathrm{sec})$ & 1 & & $\begin{array}{l}\text { Mean Difference (IV, Fixed, 95\% } \\
\mathrm{Cl} \text { ) }\end{array}$ & $\begin{array}{l}\text { Totals not select- } \\
\text { ed }\end{array}$ \\
\hline 3.1 short term (up to 1 month) & 1 & & $\begin{array}{l}\text { Mean Difference (IV, Fixed, 95\% } \\
\mathrm{Cl} \text { ) }\end{array}$ & $0.0[0.0,0.0]$ \\
\hline $\begin{array}{l}3.2 \text { medium term (> } 1 \text { month and }< \\
6 \text { months) }\end{array}$ & 1 & & $\begin{array}{l}\text { Mean Difference (IV, Fixed, 95\% } \\
\mathrm{Cl} \text { ) }\end{array}$ & $0.0[0.0,0.0]$ \\
\hline 4 Change in FVC (L) & 1 & & $\begin{array}{l}\text { Mean Difference (IV, Fixed, 95\% } \\
\mathrm{Cl} \text { ) }\end{array}$ & $\begin{array}{l}\text { Totals not select- } \\
\text { ed }\end{array}$ \\
\hline 4.1 short term (up to 1 month) & 1 & & $\begin{array}{l}\text { Mean Difference (IV, Fixed, 95\% } \\
\mathrm{Cl} \text { ) }\end{array}$ & $0.0[0.0,0.0]$ \\
\hline $\begin{array}{l}4.2 \text { medium term (> } 1 \text { month and }< \\
6 \text { months) }\end{array}$ & 1 & & $\begin{array}{l}\text { Mean Difference (IV, Fixed, 95\% } \\
\mathrm{CI})\end{array}$ & $0.0[0.0,0.0]$ \\
\hline 5 Change in $\mathrm{FEF}_{25-75 \%}(\mathrm{~L})$ & 1 & & $\begin{array}{l}\text { Mean Difference (IV, Fixed, 95\% } \\
\mathrm{Cl})\end{array}$ & $\begin{array}{l}\text { Totals not select- } \\
\text { ed }\end{array}$ \\
\hline 5.1 short term (up to 1 month) & 1 & & $\begin{array}{l}\text { Mean Difference (IV, Fixed, 95\% } \\
\mathrm{Cl} \text { ) }\end{array}$ & $0.0[0.0,0.0]$ \\
\hline $\begin{array}{l}5.2 \text { medium term (> } 1 \text { month and }< \\
6 \text { months) }\end{array}$ & 1 & & $\begin{array}{l}\text { Mean Difference (IV, Fixed, 95\% } \\
\mathrm{CI} \text { ) }\end{array}$ & $0.0[0.0,0.0]$ \\
\hline
\end{tabular}

\section{Analysis 1.1. Comparison 1 Singing versus control, Outcome 1 Change in maximal inspiratory pressure $\left(\mathrm{cm}_{2} \mathrm{O}\right)$.}

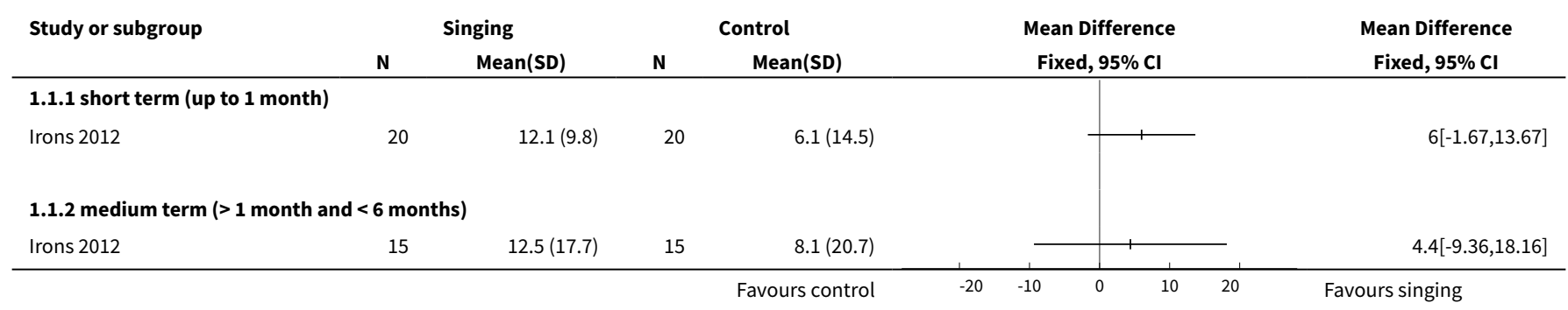

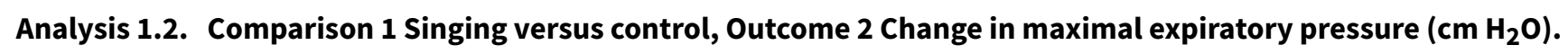

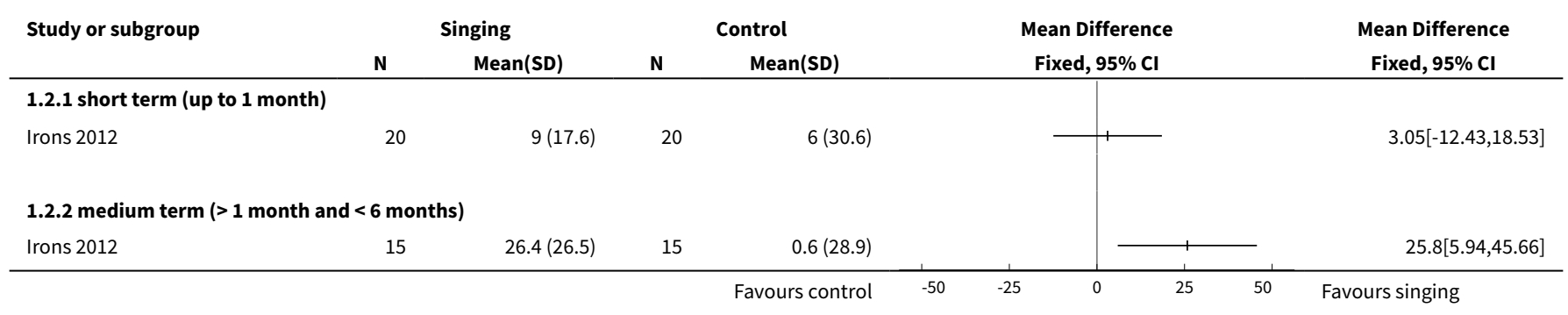


Analysis 1.3. Comparison 1 Singing versus control, Outcome 3 Change in $\mathrm{FEV}_{1}(\mathrm{~L} / \mathrm{sec})$.

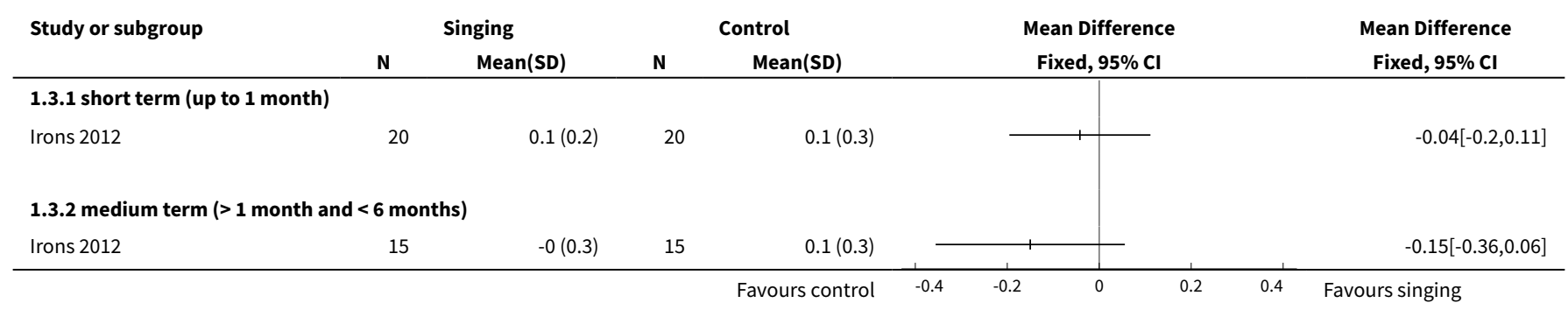

Analysis 1.4. Comparison 1 Singing versus control, Outcome 4 Change in FVC (L).

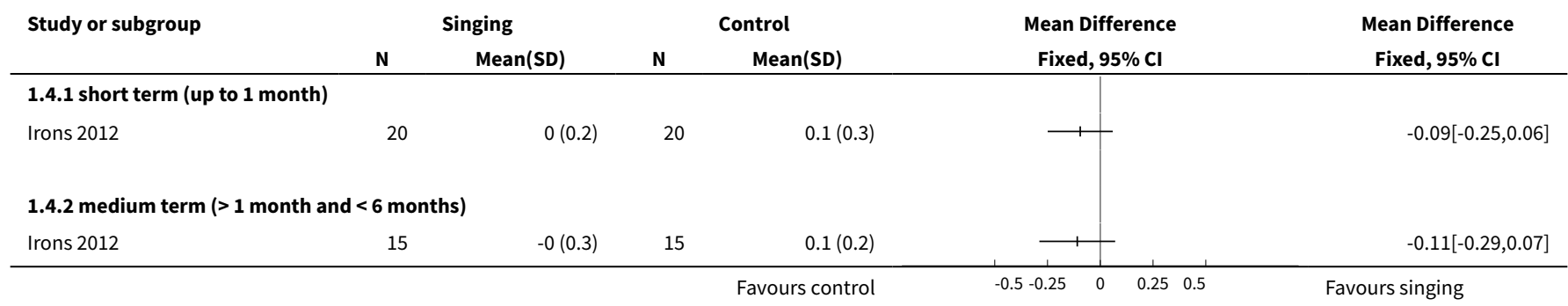

Analysis 1.5. Comparison 1 Singing versus control, Outcome 5 Change in $\mathrm{FEF}_{25-75 \%}$ (L).

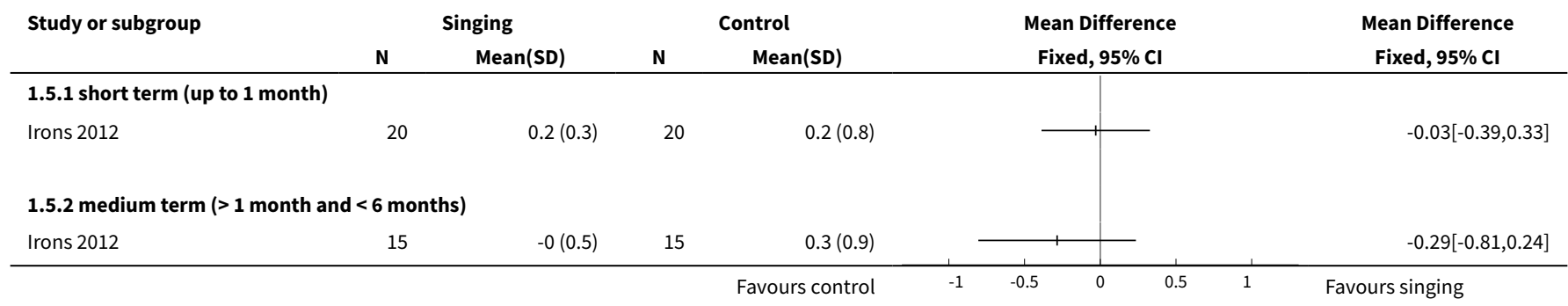

\section{ADDITIONAL TABLES}

Table 1. Glossary

\begin{tabular}{ll}
\hline Term & Explanation \\
\hline cough peak flow & highest expiratory flow generated during a forced cough manoeuvre, measured in litre per second \\
\hline visual analogue scale & $\begin{array}{l}\text { a response scale commonly used in questionnaires, to indicate levels of agreement or disagree- } \\
\text { ment to a statement on a continuous line, e.g. strongly disagree, disagree, agree, strongly agree }\end{array}$ \\
\hline
\end{tabular}


Table 2. Additional handsearching

\begin{tabular}{lc}
\hline Journal & Date searched \\
\hline Nordic Journal of Music Therapy (2003 - 2019; Vol 28 (Issue 2)) & $28 / 03 / 2019$ \\
\hline Australian Journal of Music Therapy (1996 - 2018; Vol 29) & $28 / 03 / 2019$ \\
\hline The New Zealand Journal of Music Therapy (1987 - 2018) & $28 / 03 / 2019$ \\
\hline The British Journal of Music therapy (1987 - 2018) & $28 / 03 / 2019$ \\
\hline Musiktherapeutische Umschau (German Music Therapy Journal) $(2000-2019)$ & $28 / 03 / 2019$ \\
\hline
\end{tabular}

Table 3. QoL results

\begin{tabular}{|c|c|c|c|c|c|}
\hline Domain & Time & $\begin{array}{l}\text { Treatment group } \\
\text { medians (IQR) }\end{array}$ & $\begin{array}{l}\text { Statistical } \\
\text { significance } \\
\text { in } \\
\text { change from } \\
\text { baseline }\end{array}$ & $\begin{array}{l}\text { Control group } \\
\text { medians (IQR) }\end{array}$ & $\begin{array}{l}\text { Statistical } \\
\text { significance } \\
\text { in } \\
\text { change from } \\
\text { baseline }\end{array}$ \\
\hline \multirow[t]{3}{*}{ Physical } & baseline & 80.50 (54.1 to 88.88 ) & & 72.21 (56.94 to 88.80$)$ & \\
\hline & $\begin{array}{l}\text { post-interven- } \\
\text { tion }\end{array}$ & 83.30 (62.48 to 93.74$)$ & & 83.30 (51.39 to 95.46$)$ & \\
\hline & follow up & 83.30 (70.8 to 95.83 ) & & 91.66 (75.00 to 100.00$)$ & \\
\hline \multirow[t]{3}{*}{ Emotional } & baseline & 81.65 (71.46 to 87.50$)$ & & 84.97 (60.63 to 92.88$)$ & \\
\hline & $\begin{array}{l}\text { post-interven- } \\
\text { tion }\end{array}$ & 83.30 (73.73 to 92.91$)$ & $P=0.031$ & 80.00 (64.58 to 91.65$)$ & \\
\hline & follow up & 75.00 (66.60 to 91.60$)$ & & $83.30(66.66$ to 100.00$)$ & \\
\hline \multirow[t]{3}{*}{ Social } & baseline & 71.42 (57.10 to 79.76 ) & & 71.80 (61.90 to 85.70$)$ & \\
\hline & $\begin{array}{l}\text { post-interven- } \\
\text { tion }\end{array}$ & 71.81 (62.48 to 83.30$)$ & & 66.60 (54.50 to 76.17$)$ & $P=0.044$ \\
\hline & follow up & 71.42 (66.6 to 85.71$)$ & & 72.20 (52.38 to 90.47$)$ & \\
\hline \multirow[t]{3}{*}{ Body image } & baseline & $83.29(66.62$ to 100.00$)$ & & $77.77(69.42$ to 100.00$)$ & \\
\hline & $\begin{array}{l}\text { post-interven- } \\
\text { tion }\end{array}$ & 94.44 (66.66 to 100.00$)$ & & 83.25 (66.66 to 97.22$)$ & \\
\hline & follow up & $100.00(66.60$ to 100.00$)$ & & 88.80 (77.70 to 100.00$)$ & \\
\hline \multirow[t]{2}{*}{ Eating } & baseline & $100.00(55.55$ to 100.00$)$ & & $100.00(66.62$ to 100.00$)$ & \\
\hline & $\begin{array}{l}\text { post-interven- } \\
\text { tion }\end{array}$ & $88.88(66.60$ to 100.00$)$ & & 83.29 (66.62 to 100.00$)$ & \\
\hline
\end{tabular}


Table 3. QoL results (Continued)

\begin{tabular}{|c|c|c|c|c|c|}
\hline & follow up & $88.88(66.60$ to 100.00$)$ & & $100.00(88.80$ to 100.00$)$ & \\
\hline \multirow{3}{*}{$\begin{array}{l}\text { Treatment } \\
\text { burden }\end{array}$} & baseline & 66.63 (55.50 to 77.77$)$ & & 61.08 (47.21 to 77.70$)$ & \\
\hline & $\begin{array}{l}\text { post-interven- } \\
\text { tion }\end{array}$ & 77.74 (66.62 to 97.20$)$ & $P=0.014$ & 66.60 (44.44 to 94.44$)$ & $P=0.026$ \\
\hline & follow up & $77.70(55.50$ to 100.00$)$ & $P=0.031$ & 66.60 (44.40 to 77.77$)$ & \\
\hline \multirow{3}{*}{$\begin{array}{l}\text { Respiratory } \\
\text { symptoms }\end{array}$} & baseline & 66.60 (52.08 to 77.03$)$ & & 58.30 (50.00 to 2.92 ) & \\
\hline & $\begin{array}{l}\text { post-interven- } \\
\text { tion }\end{array}$ & 80.54 (75.00 to 88.80$)$ & $P=0.001$ & 79.15 (60.38 to 87.43$)$ & $P=0.002$ \\
\hline & follow up & 83.30 (72.20 to 91.66$)$ & $P=0.016$ & 83.30 (66.60 to 88.80$)$ & $P=0.013$ \\
\hline \multirow[t]{3}{*}{ Digestion } & baseline & 83.33 (66.62 to 100.00$)$ & & 94.40 (66.60 to 100.00$)$ & \\
\hline & $\begin{array}{l}\text { post-interven- } \\
\text { tion }\end{array}$ & $100.00(88.88$ to 100.00$)$ & $P=0.024$ & 100.00 (66.62 to 100.00$)$ & \\
\hline & follow up & $100.00(88.80$ to 100.00$)$ & & 100.00 (66.66 to 100.00$)$ & \\
\hline \multirow[t]{3}{*}{ Vitality } & baseline & $45.80(33.32$ to 54.17$)$ & & 49.95 (33.32 to 64.55$)$ & \\
\hline & $\begin{array}{l}\text { post-interven- } \\
\text { tion }\end{array}$ & 41.63 (33.30 to 66.62 ) & & 66.65 (45.83 to 91.60$)$ & $P=0.043$ \\
\hline & follow up & $50.00(41.67$ to 58.33$)$ & & $75.00(49.95$ to 85.40$)$ & \\
\hline \multirow{3}{*}{$\begin{array}{l}\text { Health per- } \\
\text { ception }\end{array}$} & baseline & 61.05 (38.86 to 80.50$)$ & & 44.42 (30.53 to 80.48$)$ & \\
\hline & $\begin{array}{l}\text { post-interven- } \\
\text { tion }\end{array}$ & 61.05 (47.18 to 83.28 ) & & 77.70 (61.06 to 100.00$)$ & \\
\hline & follow up & 55.50 (33.31 to 83.29$)$ & & 88.80 (58.32 to 94.40$)$ & \\
\hline \multirow[t]{3}{*}{ Role } & baseline & 58.33 (47.90 to 77.08$)$ & & 62.47 (54.13 to 87.48$)$ & \\
\hline & $\begin{array}{l}\text { post-interven- } \\
\text { tion }\end{array}$ & $58.30(39.53$ to 66.62$)$ & & 66.63 (58.30 to 77.08 ) & \\
\hline & follow up & 75.00 (58.33 to 75.00$)$ & & 83.30 (49.95 to 95.83 ) & \\
\hline \multirow[t]{3}{*}{ Weight } & baseline & 100.00 (0.00 to 100.00$)$ & & 33.30 (24.98 to 50.00$)$ & \\
\hline & $\begin{array}{l}\text { post-interven- } \\
\text { tion }\end{array}$ & $100.00(24.98$ to 100.00$)$ & & 66.60 (33.32 to 100.00$)$ & \\
\hline & follow up & $100.00(0.00$ to 100.00$)$ & & $66.60(33.31$ to 100.00$)$ & \\
\hline
\end{tabular}

IQR: inter-quartile range 


\section{A P P E N D C E S}

\section{Appendix 1. AMED Search Strategy (searched on 28/03/2019)}

\section{AMED Search Strategy}
1. exp Cystic Fibrosis/
2. Cystic Fibrosis.tw
3. CF.tw
4. Mucoviscidosis.tw
5. 1 or 2 or 3 or 4
6. Sing or Singing or Singer ${ }^{\star}$ or Song ${ }^{\star}$. tw
7. $\left(\right.$ Vocal $^{\star}$ or breath $\left.{ }^{\star}\right)$ adj2 exercis ${ }^{\star} . t w$
8. Choir ${ }^{\star}$. tw
9. Diaphragm ${ }^{\star}$ adj2 breath*.tw
10.6 or 7 or 8 or 9
11. Exp Clinical trials/
12. Clinical trial.pt
13. Random*.tw
14. Placebo.tw
15. Crossover or Cross-over.tw
16. 11 or 12 or 13 or 14 or 15
16. 5 and 10 and 16

Key

tw: textword

Exp/: exploded AMED Thesaurus term

pt: publication type

\section{Appendix 2. PsychINFO Search Strategy (searched on 28/03/2019)}

\section{PsycINFO Search Strategy via OvidSP}
1. Cystic Fibrosis/ [PsylNFO Thesaurus Descriptor]
2. Cystic Fibrosis [keyword]
3. CF [keyword]
4. Mucoviscidosis [keyword]
5. 1 or 2 or 3 or 4 
(Continued)
6. Sing or Singing or Singer* or Song* [keyword]
7. (Vocal $^{\star}$ or breath $\left.{ }^{\star}\right) \operatorname{adj2}$ exercis ${ }^{\star}[$ keyword]
8. Choir*[keyword]
9. Diaphragm ${ }^{\star}$ adj2 breath ${ }^{\star}$ [keyword]
10. 6 or 7 or 8 or 9
11. Clinical trials [PsychINFO Thesaurus Descriptor]
12. Random* [keyword]
13. Placebo.tw [keyword]
14. Crossover or Cross-over [keyword]
15. 11 or 12 or 13 or 14
16. 5 and 10 and 15

Appendix 3. CINAHL Search Strategy (searched on 28/03/2019)

\section{CINAHL Search Strategy via EBSCO}
1. (MH "Cystic Fibrosis") [CINAHL Subject Heading]
2. Cystic Fibrosis [all text]
3. CF [all text]
4. Mucoviscidosis [all text]
5. 1 or 2 or 3 or 4
6. Sing or Singing or Singers or Song ${ }^{\star}$ [all text]
7. (Vocal $^{\star}$ or breath $\left.{ }^{\star}\right)$ adj2 exercis ${ }^{\star}[$ all text]
8. Choir ${ }^{\star}$ [all text]
9. Diaphragm ${ }^{\star}$ adj2 breath* [all text]
10.6 or 7 or 8 or 9
11. (MH "Clinical Trials+") [Exploded CINAHL Subject heading]
12. Clinical trial [publication type]
13. Random* [all text]
14. Placebo [all text]
15. Crossover or Cross-over [all text]
16. 11 or 12 or 13 or 15
17.5 and 10 and 16 
Appendix 4. ProQuest Search Strategy: Dissertation Abstracts International (late 1960 to present) (searched on 28/03/2019)

ProQuest Search Strategy: Dissertation Abstracts International (late 1960 to present)
1. [as key words in citation and abstract] Cystic fibrosis
2. [as key words in citation and abstract] Cystic fibrosis AND Breathing
3. [as key words in citation and abstract] Cystic fibrosis AND Voice
4. [as key words in citation and abstract] Cystic fibrosis AND music
5. [as key words in citation and abstract] Cystic fibrosis AND singing
6. [as key words in citation and abstract] Music therapy AND breathing
7. [as key words in citation and abstract] Singing AND breathing
8. [as key words in citation and abstract] singing OR breathing exercise AND respiratory
9. [as key words in citation and abstract] choir AND effect

Appendix 5. Clinicaltrials.gov Search Strategy (searched on 28/03/2019)

\title{
Clinicaltrials.gov Search Strategy
}

\author{
Advanced Search \\ Condition: Cystic Fibrosis \\ Interventions: sing/singing/singer/song/diaphragmatic/vocal/choir
}

\section{Appendix 6. Music therapy research database (www.musictherapyworld.de) Search Strategy (searched on 24/09/2009)}

\section{Music therapy research database (www.musictherapyworld.de) Search Strategy}

No electronic search was possible using search terms. Thus, all abstracts were reviewed.

1. Dissertations on Music Therapy (1994 - 2006)

2. Conference Reports Archive (1993 - 2001)

\section{Appendix 7. National Research Register Archive Search Strategy (2000 - 2012)}

National Research Register Archive Search Strategy 
(Continued)

cystic fibrosis AND sing OR singing OR breathing OR choir OR vocal

WHAT' S NEW

\begin{tabular}{lll}
\hline Date & Event & Description \\
\hline 3 July 2019 & New search has been performed & $\begin{array}{l}\text { A search of the Cystic Fibrosis and Genetic Disorders Review } \\
\text { Group's Cystic Fibrosis Trials Register did not identify any further } \\
\text { references which were potentially eligible for inclusion in this re- } \\
\text { view. }\end{array}$ \\
& $\begin{array}{l}\text { Additional searches run by the authors were updated. Two stud- } \\
\text { ies were found; however, they do not meet the inclusion criteria } \\
\text { and have been listed as excluded (Goldenberg 2012; Goldenberg } \\
\text { 2018). }\end{array}$ \\
\hline 3 July 2019 & $\begin{array}{l}\text { New citation required but conclusions } \\
\text { have not changed }\end{array}$ & $\begin{array}{l}\text { No new data have been added to the review, therefore our con- } \\
\text { clusions remain the same. }\end{array}$ \\
\hline
\end{tabular}

\section{H I S T O R Y}

Protocol first published: Issue 4, 2009

Review first published: Issue 5, 2010

\begin{tabular}{lll}
\hline Date & Event & Description \\
\hline 17 July 2017 & Amended & Contact details updated. \\
\hline 29 June 2017 & Amended & Contact details updated. \\
\hline 12 October 2016 & Amended & $\begin{array}{l}\text { There have been some minor amendments to the text in the } \\
\text { plain language summary. }\end{array}$ \\
\hline
\end{tabular}

18 February $2016 \quad$ New search has been performed A search of the Cystic Fibrosis and Genetic Disorders Group's Cystic Fibrosis Trials Register did not identify any new studies which were potentially relevant to this review.

The format of the plain language summary has been updated.

\begin{tabular}{lll}
\hline 18 February 2016 & $\begin{array}{l}\text { New citation required but conclusions } \\
\text { have not changed }\end{array}$ & $\begin{array}{l}\text { Since no new studies have been added to this review, our conclu- } \\
\text { sions remain the same. }\end{array}$ \\
\hline 13 April 2015 & Amended & Contact details updated. \\
\hline 31 March 2014 & New search has been performed & $\begin{array}{l}\text { A search of the Group's Cystic Fibrosis Trials Register identified } \\
\text { no new reference potentially eligible for inclusion in this review. } \\
\text { New searches including hand searching identified no new eligi- } \\
\text { ble studies to be included for this review. }\end{array}$ \\
\hline
\end{tabular}

\footnotetext{
31 March $2014 \quad$ New citation required and conclusions have changed

The previously ongoing study has been completed and results have been added to this review (Irons 2012). While no meta-
} 


\begin{tabular}{lll}
\hline Date Event $\quad$ Description
\end{tabular}

analysis was possible since there is only one study included, we have presented results in forest plots where available.

\section{CONTRIBUTIONSOF AUTHORS}

\begin{tabular}{lc}
\hline Protocol stage: draft the protocol & JY Irons, AB Chang, DT Kenny \\
\hline Review stage: select which trials to include $(2+1$ arbiter $)$ & JY Irons, AB Chang, DT Kenny \\
\hline Review stage: draft the final review & JY Irons, AB Chang, DT Kenny \\
\hline Update stage: update the review & JY Irons, AB Chang, DT Kenny, P Petocz \\
\hline
\end{tabular}

\section{DECLARATIONS OF INTEREST}

The authors of the original review have conducted the only trial included in this review - a randomised controlled trial with inpatients with CF. Clinical trial registration (ACTRN 12609000471280).

Anne Chang additionally declares that none of grants she has received relates to the intervention examined in this review.

\section{SOURCES OF SUPPORT}

\section{Internal sources}

- No sources of support supplied

\section{External sources}

- NHMRC, Australia.

AC is supported by an NHMRC practitioner fellowship (grant number 545216)

- National Institute for Health Research, UK.

This systematic review was supported by the National Institute for Health Research, via Cochrane Infrastructure funding to the Cochrane Cystic Fibrosis and Genetic Disorders Group.

\section{DIFFERENCES BETWEEN PROTOCOL AND REVIEW}

In a post hoc change, the authors considered that reporting the differences (change scores) from baseline to post-intervention or follow up, or both, in the outcome measures to be appropriate in this review.

In order to assess possible adverse effects from both treatment and control interventions "Adverse effects of the intervention" has been changed into "Adverse effects".

\section{N DEX TERMS}

\section{Medical Subject Headings (MeSH)}

Cystic Fibrosis [ ${ }^{*}$ therapy]; Music Therapy $\left[{ }^{*}\right.$ methods]; Randomized Controlled Trials as Topic

\section{MeSH check words}

Adolescent; Adult; Child; Humans 